\title{
The formation of peptide-like molecules on interstellar dust grains
}

\author{
N. F. W. Ligterink, ${ }^{1,2 \star ~ J . ~ T e r w i s s c h a ~ v a n ~ S c h e l t i n g a, ~}{ }^{1,2}$ V. Taquet, ${ }^{3}$ \\ J. K. Jørgensen, ${ }^{4}$ S. Cazaux ${ }^{5}$ E. F. van Dishoeck ${ }^{2,6}$ and H. Linnartz ${ }^{1}$ \\ ${ }^{1}$ Raymond and Beverly Sackler Laboratory for Astrophysics, Leiden Observatory, Leiden \\ University, PO Box 9513, 2300 RA Leiden, The Netherlands \\ ${ }^{2}$ Leiden Observatory, Leiden University, PO Box 9513, 2300 RA Leiden, The Netherlands \\ ${ }^{3}$ INAF-Osservatorio Astrofisico di Arcetri, Largo E. Fermi 5, I-50125, Florence, Italy \\ ${ }^{4}$ Centre for Star and Planet Formation, Niels Bohr Institute $\& 3$ Natural History Museum of Denmark, University of Copenhagen, \\ Øster Voldgade 5-7, 1350 Copenhagen K., Denmark \\ ${ }^{5}$ Faculty of Aerospace Engineering, Delft University of Technology, Delft, Netherlands \\ ${ }^{6}$ Max-Planck Institut für Extraterrestrische Physik (MPE), Giessenbachstr. 1, 85748 Garching, Germany
}

Accepted XXX. Received YYY; in original form ZZZ

\begin{abstract}
Molecules with an amide functional group resemble peptide bonds, the molecular bridges that connect amino acids, and may thus be relevant in processes that lead to the formation of life. In this study, the solid state formation of some of the smallest amides is investigated in the laboratory. To this end, $\mathrm{CH}_{4}$ : $\mathrm{HNCO}$ ice mixtures at $20 \mathrm{~K}$ are irradiated with far-UV photons, where the radiation is used as a tool to produce the radicals required for the formation of the amides. Products are identified and investigated with infrared spectroscopy and temperature programmed desorption mass spectrometry.

The laboratory data show that $\mathrm{NH}_{2} \mathrm{CHO}, \mathrm{CH}_{3} \mathrm{NCO}, \mathrm{NH}_{2} \mathrm{C}(\mathrm{O}) \mathrm{NH}_{2}, \mathrm{CH}_{3} \mathrm{C}(\mathrm{O}) \mathrm{NH}_{2}$ and $\mathrm{CH}_{3} \mathrm{NH}_{2}$ can simultaneously be formed. The $\mathrm{NH}_{2} \mathrm{CO}$ radical is found to be key in the formation of larger amides. In parallel, ALMA observations towards the low-mass protostar IRAS 16293-2422B are analysed in search of $\mathrm{CH}_{3} \mathrm{NHCHO}$ (Nmethylformamide) and $\mathrm{CH}_{3} \mathrm{C}(\mathrm{O}) \mathrm{NH}_{2}$ (acetamide). $\mathrm{CH}_{3} \mathrm{C}(\mathrm{O}) \mathrm{NH}_{2}$ is tentatively detected towards IRAS 16293-2422B at an abundance comparable with those found towards high-mass sources. The combined laboratory and observational data indicates that $\mathrm{NH}_{2} \mathrm{CHO}$ and $\mathrm{CH}_{3} \mathrm{C}(\mathrm{O}) \mathrm{NH}_{2}$ are chemically linked and form in the ice mantles of interstellar dust grains. A solid-state reaction network for the formation of these amides is proposed.
\end{abstract}

Key words: Astrochemistry - Methods: laboratory: molecular - Techniques: spectroscopic - Molecular processes - Individual objects: IRAS 16293-2422

\section{INTRODUCTION}

Prebiotic molecules are species that resemble functional groups of biogenic molecules and are thought to be involved in the formation of molecules that are relevant to life, such as amino acids, nucleobases and sugars (Herbst \& van Dishoeck 2009; Caselli \& Ceccarelli 2012). The interstellar presence of prebiotic molecules supports the idea that the building blocks of life may have an extraterrestrial origin. A number of these molecules have been detected in the InterStellar Medium (ISM), such as the simplest "sugar" glycolaldehyde

^ E-mail: ligterink@strw.leidenuniv.nl
$\left(\mathrm{CH}(\mathrm{O}) \mathrm{CH}_{2} \mathrm{OH}\right.$, Hollis et al. 2004; Jørgensen et al. 2012; Jørgensen et al. 2016) and precursor molecules to the amino acid glycine, such as methylamine $\left(\mathrm{CH}_{3} \mathrm{NH}_{2}\right.$, Kaifu et al. 1974) and aminoacetonitril $\left(\mathrm{NH}_{2} \mathrm{CH}_{2} \mathrm{CN}\right.$, Belloche et al. 2008). Among prebiotics, molecules with an amide $(-\mathrm{NH}-\mathrm{C}(\mathrm{O})-$ ) or amide-like structure, such as isocyanic acid (HNCO), hereafter generally called amides, are of particular interest because they resemble a peptide bond, see Fig 1 . In terrestrial biochemistry amino acids are connected by peptide bonds resulting in long chains which eventually form proteins, the engines of life. Reactions involving molecules with an amide functional group offer alternative pathways to form peptide chains. 


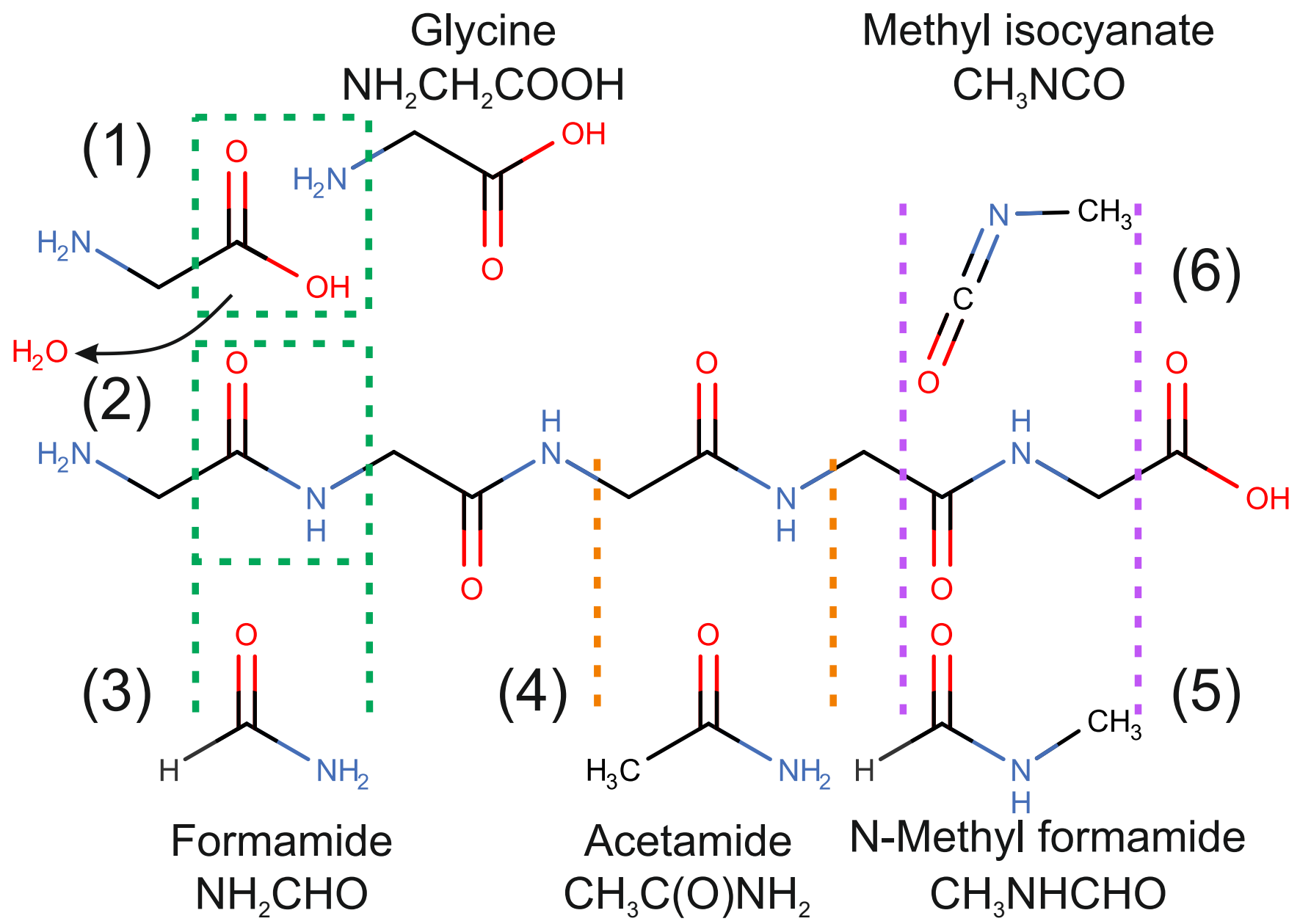

Figure 1. The reaction between the acid and base groups of two glycine molecules (1) forms a peptide bonded molecular chain (2). The peptide bond shows similarities to the smallest amide formamide (3), but the larger peptide chain incorporates structures that are similar to acetamide (4), N-methylformamide (5) and methyl isocyanate (6). Note that carbon atoms are not indicated, except for terminal groups.

Amides are widespread throughout the ISM. HNCO and formamide $\left(\mathrm{NH}_{2} \mathrm{CHO}\right)$ are the most abundant ones and have been detected in a large variety of interstellar sources (e.g. Bisschop et al. 2007; Kahane et al. 2013; Adande et al. 2013; Corby et al. 2015; Bergner et al. 2017) and comets, including 67P/Churyumov-Gerasimenko (67P/C-G, Bockelée-Morvan et al. 2000; Goesmann et al. 2015; Altwegg et al. 2017). Observational evidence exists for a chemical relationship between $\mathrm{HNCO}$ and $\mathrm{NH}_{2} \mathrm{CHO}$, which is thought to originate in interstellar ice (Bisschop et al. 2007; López-Sepulcre et al. 2015; Coutens et al. 2016). In the form of the $\mathrm{OCN}^{-}$anion, $\mathrm{HNCO}$ has been directly detected in interstellar ices at abundances as high as $2 \%$ with respect to water (Lacy et al. 1984; Gibb et al. 2004; van Broekhuizen et al. 2005). Tentatively, the presence of formamide in interstellar ice has been claimed towards NGC 7538 IRS9 (Raunier et al. 2004).

The more complex molecule acetamide $\left(\mathrm{CH}_{3} \mathrm{C}(\mathrm{O}) \mathrm{NH}_{2}\right)$ has been detected towards Sagittarius B2 (Sgr B2) and Orion KL (Hollis et al. 2006; Cernicharo et al. 2016; Belloche et al. 2017) and on 67P/C-G (Goesmann et al. 2015; Altwegg et al. 2017). Formation of this molecule has been linked to that of formamide (Halfen et al. 2011), although it is inconclusive whether gas-phase or solid-state chemistry is involved (see also Quan \& Herbst 2007). Methyl isocyanate $\left(\mathrm{CH}_{3} \mathrm{NCO}\right)$ has been detected towards Sgr B2 and Orion KL (Halfen et al. 2015; Cernicharo et al. 2016) and recently towards the sun-like protostar IRAS 16293-2422 (Ligterink et al. 2017; Martín-Doménech et al. 2017). Its formational origin is likely found in interstellar ices, although some non-negligible gas-phase production routes are available (Quénard et al. 2018). Hydrogenation of $\mathrm{CH}_{3} \mathrm{NCO}$ is hypothesised to lead to $\mathrm{N}$-methylformamide $\left(\mathrm{CH}_{3} \mathrm{NHCHO}\right)$, a molecule that has tentatively been detected towards Sgr B2 (Belloche et al. 2017). Carbamide, also known as urea $\left(\mathrm{NH}_{2} \mathrm{C}(\mathrm{O}) \mathrm{NH}_{2}\right)$, has tentatively been identified towards Sgr B2 as well (Remijan et al. 2014). Finally, cyanamide $\left(\mathrm{NH}_{2} \mathrm{CN}\right)$ has been observed towards various galactic and extragalactic sources (e.g. Turner et al. 1975; Martín et al. 2006; Coutens et al. 2018).

The high interstellar abundances of HNCO and $\mathrm{NH}_{2} \mathrm{CHO}$ have resulted in many solid-state laboratory studies with the aim to understand their formation (Hagen 
et al. 1979; Gerakines et al. 2004; Raunier et al. 2004; Jones et al. 2011; Islam et al. 2014; Muñoz Caro et al. 2014; Fedoseev et al. 2015; Noble et al. 2015; Fedoseev et al. 2016; Kaňuchová et al. 2016; Fedoseev et al. 2018). In these studies, ice mixtures containing a source of carbon, like $\mathrm{CH}_{3} \mathrm{OH}$ or $\mathrm{CO}$, and a source of nitrogen, such as $\mathrm{HCN}$, $\mathrm{HNCO}, \mathrm{NH}_{3}, \mathrm{~N}_{2}$ or $\mathrm{NO}$ are hydrogenated and/or energetically processed. A number of mechanisms have been shown to produce these species, such as the $\mathrm{NH}+\mathrm{CO}$ reaction to produce $\mathrm{HNCO}$ (Fedoseev et al. 2015) and the $\mathrm{NH}_{2}$ $+\mathrm{CHO}$ radical combination to produce $\mathrm{NH}_{2} \mathrm{CHO}$ (Jones et al. 2011). Raunier et al. (2004) proposed that HNCO can be hydrogenated to $\mathrm{NH}_{2} \mathrm{CHO}$ by hot $\mathrm{H}$-atom addition (i.e. hydrogen atoms produced by energetic dissociation processes that carry enough excess energy to overcome reaction barriers). On the other hand, Noble et al. (2015) showed that hydrogenation of HNCO with "cold" ( 300 K) hydrogen atoms produced in a beam line does not result in the formation of $\mathrm{NH}_{2} \mathrm{CHO}$.

The larger amides $\mathrm{NH}_{2} \mathrm{C}(\mathrm{O}) \mathrm{NH}_{2}$ and $\mathrm{CH}_{3} \mathrm{C}(\mathrm{O}) \mathrm{NH}_{2}$ have been produced in various ice experiments (e.g. Berger 1961; Agarwal et al. 1985; Bernstein et al. 1995; Raunier et al. 2004; Henderson \& Gudipati 2015; Förstel et al. 2016), but formation mechanisms have not been extensively investigated. Some reactions have been proposed, such as the $\mathrm{NH}_{2}$ $+\mathrm{NH}_{2} \mathrm{CO}$ radical addition to form $\mathrm{NH}_{2} \mathrm{C}(\mathrm{O}) \mathrm{NH}_{2}$ (Agarwal et al. 1985; Raunier et al. 2004). Modelling investigations have predicted the formation of $\mathrm{CH}_{3} \mathrm{C}(\mathrm{O}) \mathrm{NH}_{2}$ through the $\mathrm{CH}_{3}+\mathrm{HNCO}$ reaction followed by hydrogenation (Garrod et al. 2008) or the hydrogen abstraction of $\mathrm{NH}_{2} \mathrm{CHO}$ followed by $\mathrm{CH}_{3}$ addition (Belloche et al. 2017). The formation of $\mathrm{CH}_{3} \mathrm{NHCHO}$ has been claimed in far-UV (also known as vacuum-UV or $\mathrm{V}-\mathrm{UV}$ ) irradiated $\mathrm{CH}_{3} \mathrm{NH}_{2}$ : $\mathrm{CO}$ ice mixtures through the reaction $\mathrm{CH}_{3} \mathrm{NH}+\mathrm{CHO}$ (Bossa et al. 2012), while modelling investigations have shown that hydrogenation of $\mathrm{CH}_{3} \mathrm{NCO}$ is one of the main channels of $\mathrm{CH}_{3} \mathrm{NHCHO}$ formation (Belloche et al. 2017). Recently, the solid-state reaction $\mathrm{CH}_{3}+(\mathrm{H}) \mathrm{NCO}$ was proposed as the most likely candidate to explain the formation of $\mathrm{CH}_{3} \mathrm{NCO}$ (Ligterink et al. 2017). Other solid-state pathways, such as formation via a HCN $\cdots \mathrm{CO}$ van der Waals complex, have also been proposed as relevant pathways in modelling studies (Majumdar et al. 2018).

The aim of this work is to elucidate the chemical network that links various small amides that have been detected in the ISM and explain their formation. This work is complementary to that of Ligterink et al. (2017) on $\mathrm{CH}_{3} \mathrm{NCO}$ and investigates reactions that can occur simultaneously with the formation of this molecule. Ice mixtures of $\mathrm{CH}_{4}: \mathrm{HNCO}$, two astronomically relevant precursor species, are irradiated with far-UV radiation. The far-UV radiation is used as a tool to form radicals, which engage in recombination reaction to form amides, amines and other molecules. On interstellar dust grains these radicals could be formed by far-UV photodissociation, but also non-energetically by hydrogenation of atomic carbon, oxygen and nitrogen.

This paper is organised in the following way. Section 2 discusses the laboratory set-up and measurement protocol. The results of the experiments are presented in Sec. 3. Observations and the comparison between laboratory and observational results are presented in Sec. 4 , followed by the
Table 1. Overview of performed far-UV irradiation experiments on ice mixtures.

\begin{tabular}{lllll}
\hline \hline Exp. & $\begin{array}{c}N(\mathrm{HNCO}) \\
\text { ML }\left(10^{15}\right.\end{array}$ & $\begin{array}{l}N\left(\mathrm{CH}_{4}\right) \\
\left.\text { molecules } \mathrm{cm}^{-2}\right)\end{array}$ & $\begin{array}{l}N(\mathrm{CO})^{a} \\
\text { High/Low }\end{array}$ \\
\hline 1 & 14.3 & 17.0 & - & $\mathrm{H}$ \\
2 & 17.4 & - & - & $\mathrm{H}$ \\
3 & 15.1 & $15.7^{b}$ & - & $\mathrm{H}$ \\
\hline 4 & 29.9 & 5.5 & - & $\mathrm{H}$ \\
5 & 11.4 & 24.6 & - & $\mathrm{L}$ \\
\hline 6 & 2.9 & 8.5 & 95.6 & $\mathrm{~L}$ \\
7 & 4.8 & 13.9 & 164.2 & $\mathrm{~L}$ \\
\hline
\end{tabular}

Notes. ${ }^{a}$ Total ${ }^{12+13} \mathrm{CO}$ column density calculated from the ${ }^{13} \mathrm{CO}$ band multiplied by $91 .{ }^{b}$ Experiment using ${ }^{13} \mathrm{CH}_{4}$, the bandstrength value of $1.1 \times 10^{-17} \mathrm{~cm}$ molecule ${ }^{-1}$ is assumed to apply to the ${ }^{13} \mathrm{CH}_{4}$ degenerate stretching mode as well. Other bandstrength values are found in Table 2 .

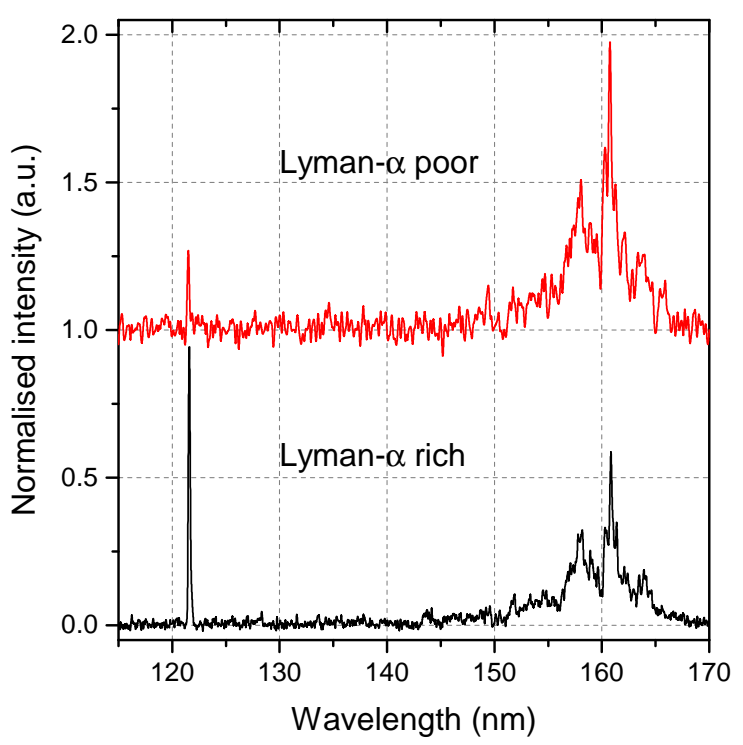

Figure 2. Far-UV spectrum of the MDHL emission between 115 and $170 \mathrm{~nm}$. The top spectrum (red) shows lamp emission poor in Lyman- $\alpha$, while the bottom spectrum (black) shows lamp emission rich in Lyman- $\alpha$.

discussion in Sec. 5. The conclusions of this work are presented in Sec. 6.

\section{EXPERIMENTAL}

\subsection{Set-up and protocol}

For this study the CryoPAD2 set-up in the Sackler Laboratory for Astrophysics is used, which has been described in 
Table 2. Peak positions and transmission bandstrengths of precursor and product species

\begin{tabular}{|c|c|c|c|c|c|}
\hline \multirow[t]{2}{*}{ Species } & \multirow[t]{2}{*}{ Name } & \multirow[t]{2}{*}{ band } & \multicolumn{2}{|c|}{$\begin{array}{c}\text { Peak position } \\
\left(\mathrm{cm}^{-1}\right)\end{array}$} & \multirow{2}{*}{$\begin{array}{l}\text { Bandstrength } \\
\mathrm{cm} \text { molecule } \\
\text { Transmission }\end{array}$} \\
\hline & & & Literature & Experiment* & \\
\hline HNCO (water poor) & Isocyanic acid & OCN str. ${ }^{a}$ & 2260 & 2266 & $7.8 \times 10^{-17}$ \\
\hline $\mathrm{CH}_{4}$ & Methane & d-str. ${ }^{b}$ & 1301 & 1302 & $7.3 \times 10^{-18}$ \\
\hline $\mathrm{CH}_{4}$ & Methane & $\mathrm{d}$-str. ${ }^{b}$ & 3010 & 3010 & $1.1 \times 10^{-17}$ \\
\hline $\mathrm{CO}$ & Carbon monoxide & $\mathrm{CO}$ str. ${ }^{c}$ & 2138 & 2142 & $1.1 \times 10^{-17}$ \\
\hline $\mathrm{OCN}^{-}$(water poor) & Cyanate anion & OCN str. ${ }^{a}$ & 2160 & 2170 & $1.3 \times 10^{-16}$ \\
\hline $\mathrm{CO}_{2}$ & Carbon dioxide & $\mathrm{CO}$ a-str. ${ }^{c}$ & 2342 & 2341 & $7.6 \times 10^{-17}$ \\
\hline $\mathrm{HCN}$ & Hydrogen cyanide & $\mathrm{CN}$ str. $^{d * *}$ & 2099 & 2108 & - \\
\hline $\mathrm{CH}_{3} \mathrm{NCO}$ & Methyl isocyanate & $\mathrm{NCO}$ a-str..$^{e * *}$ & 2322 & 2322 & - \\
\hline $\mathrm{CH}_{3} \mathrm{CH}_{3}$ & Ethane & $\mathrm{CH}_{3}$ d-str. ${ }^{f}$ & 2975 & 2976 & $6.5 \times 10^{-18}$ \\
\hline $\mathrm{NH}_{4}^{+}$ & Ammonium cation & deform. $^{a}$ & 1485 & 1466 & $4.6 \times 10^{-17}$ \\
\hline $\mathrm{NH}_{2} \mathrm{CHO}$ & Formamide & CO str. ${ }^{g, h}$ & 1700 & $\sim 1687$ & $3.3 \times 10^{-17}$ \\
\hline $\mathrm{NH}_{2} \mathrm{CONH}_{2}$ & Carbamide & CO str. ${ }^{h}$ & 1590 & - & - \\
\hline $\mathrm{NH}_{2} \mathrm{CONH}_{2}$ & Carbamide & NH sym. bend ${ }^{h}$ & 1675 & $\sim 1687$ & - \\
\hline $\mathrm{NH}_{2} \mathrm{CONH}_{2}$ & Carbamide & $\mathrm{NH}$ asym. bend ${ }^{h}$ & 1630 & $\sim 1687$ & - \\
\hline
\end{tabular}

Notes. ${ }^{*}$ Peak positions found for experiment 1 (see Table 1 ); ${ }^{* *}$ Indicates IR data obtained from reflection experiments. ${ }^{a}$ van Broekhuizen et al. (2004); ${ }^{b}$ Hudgins et al. (1993); Boogert et al. (1997); ${ }^{c}$ Bouilloud et al. (2015); ${ }^{d}$ Gerakines et al. (2004); ${ }^{e}$ Ligterink et al. (2017); ${ }^{f}$ Gerakines et al. (1996); ${ }^{g}$ Wexler (1967); ${ }^{h}$ Raunier et al. (2004)

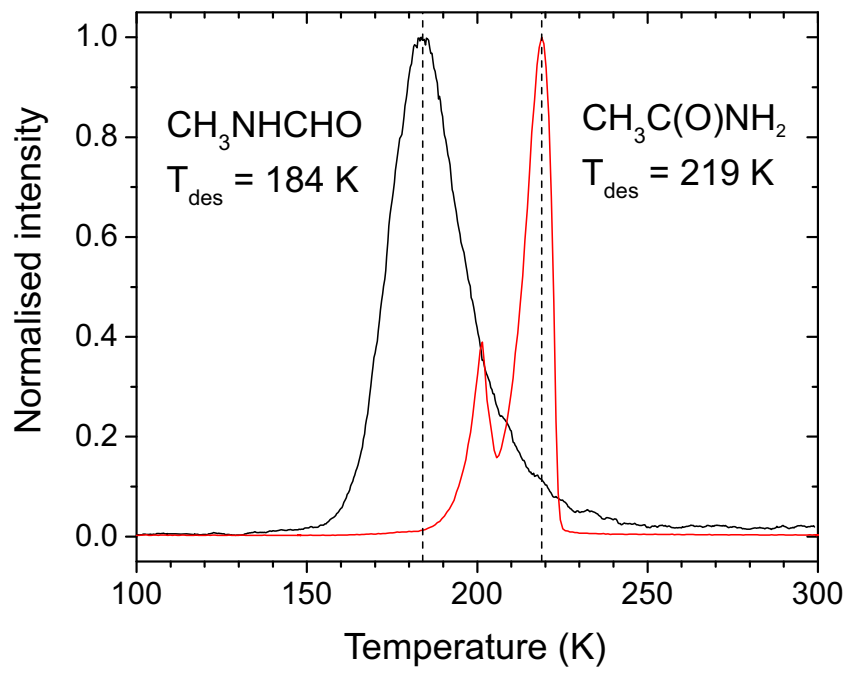

Figure 3. TPD traces of $m / z 59$ of pure $\mathrm{CH}_{3} \mathrm{NHCHO}$ (black) and pure $\mathrm{CH}_{3} \mathrm{C}(\mathrm{O}) \mathrm{NH}_{2}$ (red). Note that $\mathrm{CH}_{3} \mathrm{C}(\mathrm{O}) \mathrm{NH}_{2}$ has a double desorption peak with the first peak potentially caused by a phase change in the ice.

Ligterink et al. (2017, 2018). In short, it consists of a central chamber at ultra-high vacuum conditions $\left(P \leq 10^{-10} \mathrm{mbar}\right)$. A gold-coated, reflective surface is positioned at the center of the chamber, which is cryogenically cooled to temperatures as low as $12 \mathrm{~K}$. Gases are directly deposited (as opposed to background deposition) on this surface, forming an ice layer which simulates the ice mantles on interstellar dust grains. The output of a Microwave Discharge Hydrogen-flow Lamp (MDHL, Ligterink et al. 2015, and references therein) is directed at the surface and used to energetically process the ice with far-UV radiation $(10.2-7.3 \mathrm{eV})$. Chemical changes within the ice are traced by Reflection Absorption IR Spec- troscopy (RAIRS) and mass spectrometry in combination with Temperature Programmed Desorption (TPD).

Hydrogen lamps generally have strong emission at the Lyman- $\alpha$ transition at $121.6 \mathrm{~nm}$ and $\mathrm{H}_{2}$ continuum emission between 140-160 nm. In this work lamp conditions which result in Lyman- $\alpha$ rich or poor emission (see Fig. 2) are used to process the ice samples in order to test the influence of high energy Lyman- $\alpha$ radiation on the solid-state chemistry. In experiments on mixed $\mathrm{CH}_{4}$ : $\mathrm{HNCO}$ ices, far- $\mathrm{UV}$ radiation can produce a number of radicals and molecules, such as $\mathrm{H}, \mathrm{N}, \mathrm{HN}$ and $\mathrm{CO}$ from HNCO (Raunier et al. 2004) or $\mathrm{CH}_{2}$ and $\mathrm{CH}_{3}$ from $\mathrm{CH}_{4}$ (Bossa et al. 2015). Production of these radicals is influenced by the spectral energy distribution of the lamp. For example, the $\mathrm{CH}_{4}$ photo-absorption cross section is high around the Lyman- $\alpha$ transition, but low for wavelengths longer than $140 \mathrm{~nm}$ (Cruz-Diaz et al. 2014), which will result in limited or no production of $\mathrm{CH}_{2}$ and $\mathrm{CH}_{3}$ radicals for Lyman- $\alpha$ poor conditions. The total photon flux of the lamp at the position of the ice sample is $(1.1 \pm 0.1) \times 10^{14}$ photons $\mathrm{s}^{-1}$ for the Lyman- $\alpha$ rich emission, while it is $(6.1 \pm 1.0) \times 10^{13}$ photons $\mathrm{s}^{-1}$ in the Lyman- $\alpha$ poor case.

Gases used during the experiments are $\mathrm{CH}_{4}$ (Linde Gas, 99.995\% purity), ${ }^{13} \mathrm{CH}_{4}$ (Sigma-Aldrich, $99 \%$ purity) and CO (Linde Gas, $99.995 \%$ purity). Regular methane gas contains the natural isotope ratio of ${ }^{12 / 13} \mathrm{C}$ of $\sim 90$. Throughout this paper regular methane gas will generally be called ${ }^{12} \mathrm{CH}_{4}$ to emphasize the mass difference in experiments making use of either ${ }^{12} \mathrm{C}$ or ${ }^{13} \mathrm{C}$ labelled $\mathrm{CH}_{4}$. Gas-phase $\mathrm{HNCO}$ is produced by thermal decomposition of cyuranic acid (Sigma-Aldrich, 98\% purity), the solid trimer of HNCO, following a similar protocol as van Broekhuizen et al. (2004). Freeze-pump-thaw cycles are used to purify the HNCO sample and mainly remove $\mathrm{CO}_{2}, \mathrm{O}_{2}$ and $\mathrm{N}_{2}$ contamination. Hydrogen cyanide ( $\mathrm{HCN})$ impurities are sometimes present in the prepared gas, but can not be removed by this technique. 
Samples of solid acetamide (Sigma-Aldrich, 99\% purity), liquid formamide (Sigma-Aldrich, 99\% purity) and liquid Nmethylformamide (Sigma-Aldrich, 99\% purity) are used for verification experiments.

Gas mixtures are prepared in a gas mixing line by volume mixing, with volumes determined by a gas independent gauge. The mixture is deposited on the substrate at $20 \mathrm{~K}$. Residual gases of the deposition are removed from the chamber during a short waiting period until a pressure of $\sim 1 \times 10^{-10}$ mbar is reached. Next, the samples are UV irradiated for 20 minutes, corresponding to a total fluence of $(1.3 \pm 0.1) \times 10^{17}$ or $(7.3 \pm 1.2) \times 10^{16}$ photons for the Lyman- $\alpha$ rich and poor case, respectively. Assuming a dark cloud farUV flux of $10^{4}$ photons $^{-1}$ (Shen et al. 2004), this matches a dark cloud lifetime of about $3 \times 10^{5}$ years. After irradiation, Temperature Programmed Desorption (TPD) is employed to linearly heat the sample from 20 to $300 \mathrm{~K}$ and let the ice contents desorb from the surface. Material released to the gas-phase is analysed with a high sensitivity Quadrupole Mass Spectrometer (QMS). After deposition, during irradiation and during TPD, IR spectra are recorded at 1 or $2 \mathrm{~cm}^{-1}$ resolution using a Fourier Transform InfraRed Spectrometer (FTIRS, 500-4000 $\mathrm{cm}^{-1}$ ), to trace chemical changes in the ice. An overview of the performed irradiation experiments is given in Table 1. A number of experiments makes use of a $\mathrm{CO}$ matrix that isolates produced radicals and can act as a medium to thermalise hot, energetic, $\mathrm{H}$-atoms.

\subsection{RAIR spectroscopy analysis method}

RAIR spectra of the experiments are baseline subtracted and IR features are identified by comparing with literature data. Generally small deviations between literature values and this work can arise from differences in transmission versus reflection spectroscopy or matrix effects. The column density $\left(N_{\text {species }}\right)$ of a molecule is determined from the integrated band area $\left(\int_{\text {band }} \log _{10}\left(\frac{I_{0}(\tilde{v})}{I(\tilde{v})}\right) d \tilde{v}\right)$ of an IR feature by:

$N_{\text {species }}=\frac{1.1}{3.4} \ln (10) \frac{\int_{\text {band }} \log _{10}\left(\frac{I_{0}(\tilde{v})}{I(\tilde{v})}\right) d \tilde{v}}{A_{\text {band }}^{\prime}}$,

where $A_{\text {band }}^{\prime}$ is the bandstrength of a specific band of a molecule and $\frac{1.1}{3.4}$ is a set-up specific RAIRS scaling factor. Due to longer pathlength through the ice and dipole surface coupling effects, RAIRS has higher sensitivity compared to transmission IR spectroscopy and therefore bandstrength values differ from transmission bandstrength values. For the CryoPAD2 set-up, the bandstrength of the CO stretch mode of carbon monoxide at $2138 \mathrm{~cm}^{-1}$ was determined to be $3.4_{-0.5}^{+0.5} \times 10^{-17} \mathrm{~cm}$ molecule ${ }^{-1}$ (Ligterink et al. 2018 ). Using the transmission bandstrength of $1.1 \times 10^{-17} \mathrm{~cm}$ molecule ${ }^{-1}$ for the same CO mode (Bouilloud et al. 2015) and assuming that for identical conditions bandstrengths of other molecules scale approximately in the same way, this scaling factor between RAIRS and transmission IR spectroscopy of $\frac{1.1}{3.4}$ has been derived.

Table 2 gives an overview of band positions and used bandstrength values of precursor and expected product species. Most IR parameters are taken from transmission experiments available from literature, with the exception of the $\mathrm{CN}$ stretching mode of $\mathrm{HCN}$ and the $\mathrm{NCO}$ asymmetric stretching mode of $\mathrm{CH}_{3} \mathrm{NCO}$ (Gerakines et al. 2004; Ligterink et al. 2017, respectively). Because no water ice is used in these experiments, the water-poor bandstrength values listed by van Broekhuizen et al. (2004) are used for HNCO and $\mathrm{OCN}^{-}$.

Recently, $\mathrm{CH}_{4}$ has been under discussion due to inconsistencies in the literature on the assignment of $\mathrm{CH}_{4}$ IR bands to the amorphous or crystalline phase and subsequent deviations in bandstrengths (Gerakines \& Hudson 2015). Experiments in this work are conducted with ices at temperatures of $20 \mathrm{~K}$ and therefore $\mathrm{CH}_{4}$ is considered to be of crystalline nature. Consequently, a crystalline bandstrength value is used, by applying the same correction as performed by Boogert et al. (1997) on data recorded by Hudgins et al. (1993) to retrieve the bandstrength for the $\mathrm{CH}_{4}$ mode at $3010 \mathrm{~cm}^{-1}$ as $1.1 \times 10^{-17} \mathrm{~cm}$ molecule ${ }^{-1}$.

\subsection{Temperature Programmed Desorption method}

During TPD, precursor and product species desorb from the gold surface and are measured by the QMS, with an ionization source tuned to $70 \mathrm{eV}$. A temperature ramp of $5 \mathrm{~K}$ $\mathrm{min}^{-1}$ is used. The mass spectrometric data are corrected for the QMS work function (i.e. the set-up specific response to a certain $m / z$ ). Products are identified by a combination of their characteristic desorption temperatures and fragmentation patterns. Identification can be hindered if molecules have similar desorption temperatures, fragmentation patterns or co-desorb with other species. Particularly the precursor species HNCO, which desorbs around $130 \mathrm{~K}$, contaminates the TPD signal of other species. Due to its high abundance compared to products, even small fragmentation channels of HNCO, for example at $m / z, 28$ and 29, contribute significantly to product fragmentation patterns and make it impossible to disentangle precursor and product. Therefore, the focus of the TPD data is mainly on the region between 150 and $300 \mathrm{~K}$, avoiding the HNCO desorption peak as much as possible. In addition, isotopic labelling is used to distinguish products by mass shifts.

In this work the intensity of a fragment at a certain $\mathrm{m} / \mathrm{z}$ is determined by integrating the area under its baseline subtracted desorption peak. Ratios between two or more molecules can be determined from mass fragments that can be uniquely assigned to a single molecule. Ratios are affected by the fact that products desorbing from the gold substrate can again freeze-out at another cold location, mainly the heat shield $(T \approx 70 \mathrm{~K})$. Particularly when comparing the gas-phase ratio of a volatile species like $\mathrm{CO}\left(T_{\mathrm{des}}=30 \mathrm{~K}\right)$ with a non-volatile species such as $\mathrm{H}_{2} \mathrm{O}\left(T_{\text {des }}=150 \mathrm{~K}\right)$, the ratio can be offset by freeze-out. Since in this work relatively non-volatile species $\left(T_{\text {des }} \geq 100 \mathrm{~K}\right)$ are studied we assume that all these species have a similar freeze-out efficiency and thus the measured ratios between these molecules are not strongly affected. When the fragmentation pattern and electron impact absorption cross section of a molecule are taken into account, the ratio between two molecular mass fragments can be converted in an absolute abundance ratio $(A R)$ with the following equation:

$A R=\frac{I_{m / z, \text { molecule1 }}}{I_{m / z, \text { molecule2 }}} \frac{\phi_{m / z, \text { molecule2 }}}{\phi_{m / z, \text { molecule1 }}} \frac{\sigma_{\text {molecule2 }}}{\sigma_{\text {molecule } 1}}$, 


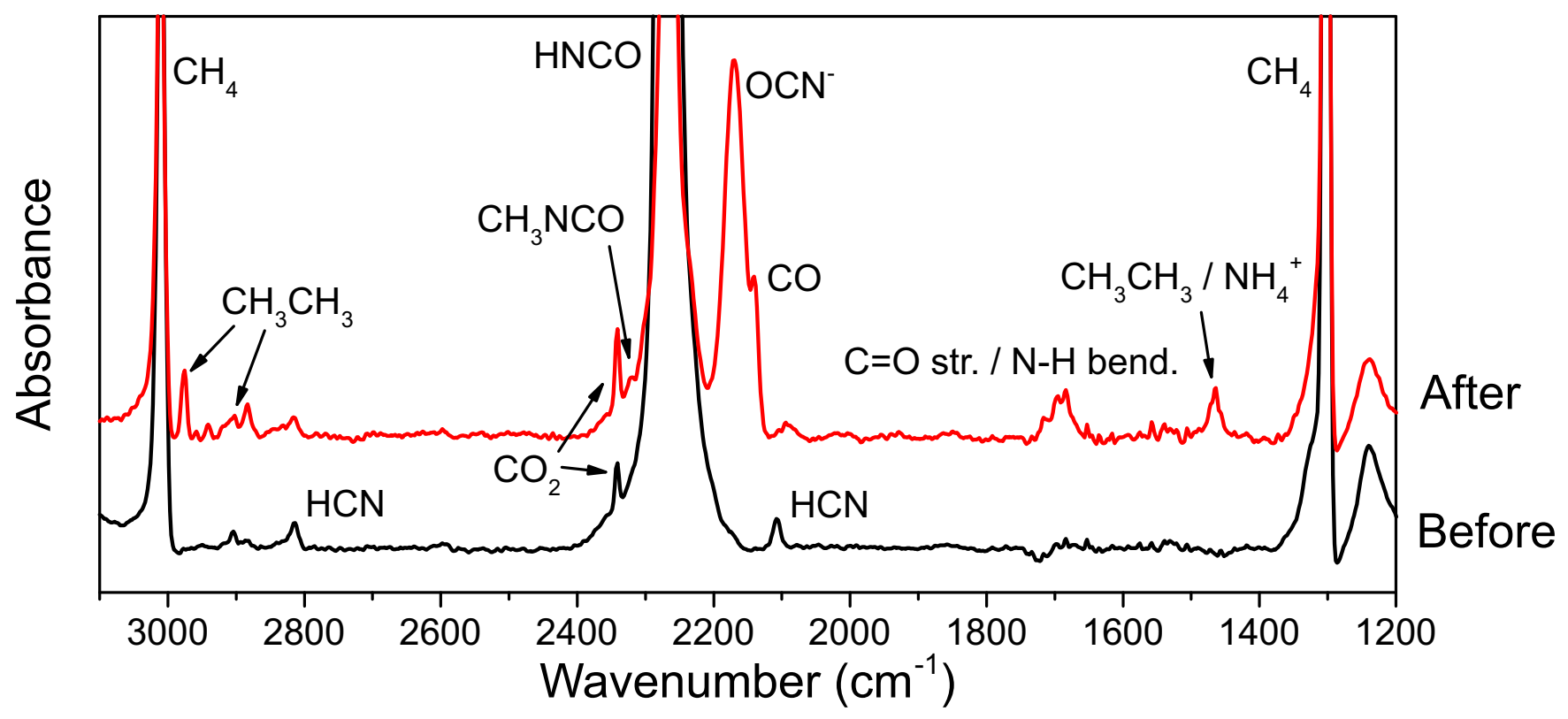

Figure 4. IR spectrum between 3100 and $1200 \mathrm{~cm}^{-1}$ before (black) and after (red) irradiation of the HNCO: ${ }^{12} \mathrm{CH}_{4}$ ice mixture (Exp. 1).

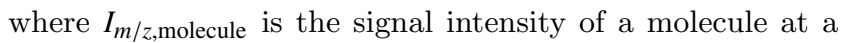

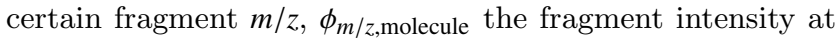
this $\mathrm{m} / \mathrm{z}$ and $\sigma_{\text {molecule }}$ the total electron impact absorption cross section of the molecule at $70 \mathrm{eV}$ ionization energy.

\subsection{Fragmentation patterns and desorption temperatures}

Identification of products relies for a large part on molecule specific mass fragmentation patterns and desorption temperatures. Most fragmentation patterns of precursor and possible product species are available in the NIST database ${ }^{1}$, listed for an ionization energy of $70 \mathrm{eV}$. For HNCO the fragmentation pattern given in Bogan \& Hand (1971) is used. Desorption temperatures of many small species, like CO, water or methanol, have been well studied (e.g. Collings et al. 2004). However, for larger species such data are often not available, including the two potential products $\mathrm{CH}_{3} \mathrm{NHCHO}$ and $\mathrm{CH}_{3} \mathrm{C}(\mathrm{O}) \mathrm{NH}_{2}$. In order to obtain the desorption temperature and fragmentation pattern of these species, samples of pure $\mathrm{CH}_{3} \mathrm{NHCHO}$ and $\mathrm{CH}_{3} \mathrm{C}(\mathrm{O}) \mathrm{NH}_{2}$ are deposited at $20 \mathrm{~K}$ in the CryoPAD2 set-up and their desorption is measured during TPD. Figure 3 shows their TPD traces at $\mathrm{m} / \mathrm{z}$ 59 , the main detection mass of both molecules. The peak desorption temperature of $\mathrm{CH}_{3} \mathrm{NHCHO}$ is found at $184 \mathrm{~K}$, while $\mathrm{CH}_{3} \mathrm{C}(\mathrm{O}) \mathrm{NH}_{2}$ desorbs at $219 \mathrm{~K}$. The origin of the smaller peak at $\sim 200 \mathrm{~K}$ in the $\mathrm{CH}_{3} \mathrm{C}(\mathrm{O}) \mathrm{NH}_{2}$ TPD trace is unknown, but could be the result of $\mathrm{CH}_{3} \mathrm{C}(\mathrm{O}) \mathrm{NH}_{2}$ desorption due to the amorphous to crystalline phase change in the ice. Another important product is $\mathrm{NH}_{2} \mathrm{CHO}$, for which

1 NIST Mass Spec Data Center, S.E. Stein, director, "Mass Spectra" in NIST Chemistry WebBook, NIST Standard Reference Database Number 69, Eds. P.J. Lindstrom and W.G. Mallard, National Institute of Standards and Technology, Gaithersburg MD, 20899, http://webbook.nist.gov. the desorption temperature is determined to be $210 \mathrm{~K}$ (see Fig. A1 in Appendix A). Measured fragmentation patterns of $\mathrm{CH}_{3} \mathrm{NHCHO}$ and $\mathrm{CH}_{3} \mathrm{C}(\mathrm{O}) \mathrm{NH}_{2}$ are presented in Appendix $\mathrm{A}$.

\section{RESULTS}

The identification of products in the far-UV processed $\mathrm{CH}_{4}$ :HNCO mixed ices is based on a series of experiments for three primary ice settings. These are a 1:1 $\mathrm{HNCO}:{ }^{12} \mathrm{CH}_{4}$ mixed ice, a pure HNCO ice and a $1: 1 \mathrm{HNCO}:{ }^{13} \mathrm{CH}_{4}$ mixture. Table 1 lists these as Exps. 1 to 3, together with other experiments performed in this work to test the influence of Lyman- $\alpha$ radiation and $\mathrm{CO}$ matrix effects. In the following sections the IR spectroscopic data of Exp. 1 and mass spectrometric data of Exps. 1 to 3 are analysed.

\subsection{IR analysis of UV processed ices}

Figure 4 shows the RAIR spectra between 3100 and 1200 $\mathrm{cm}^{-1}$ of the HNCO: $\mathrm{CH}_{4}$ mixture (Exp. 1) before and after far-UV irradiation with a total photon fluence of $(1.3 \pm 0.1) \times 10^{17}$. Before irradiation, bands of HNCO (2266 $\left.\mathrm{cm}^{-1}\right)$ and $\mathrm{CH}_{4}\left(3010\right.$ and $\left.1302 \mathrm{~cm}^{-1}\right)$ are visible. Small features of $\mathrm{HCN}\left(2825\right.$ and $\left.2108 \mathrm{~cm}^{-1}\right)$ and $\mathrm{CO}_{2}\left(2341 \mathrm{~cm}^{-1}\right)$ are visible as well and are contaminants of the HNCO production process.

After irradiation, bands appear of newly formed products, most of which are found in processed samples of pure $\mathrm{CH}_{4}$ or pure $\mathrm{HNCO}$ as well. These species are ethane $\left(\mathrm{CH}_{3} \mathrm{CH}_{3}\right), \mathrm{OCN}^{-} \mathrm{NH}_{4}^{+}$and $\mathrm{CO}$. The presence of these products indicates that the $\mathrm{CH}_{3}$ radical is formed from $\mathrm{CH}_{4}$ and that HNCO fragments into $\mathrm{CO}$ and $\mathrm{NH}$ (or N and $\mathrm{H}$ separately). The $\mathrm{NH}$ radical reacts sequentially with $\mathrm{H}$ atoms to form $\mathrm{NH}_{3}$, which engages in an acid-base reaction with 


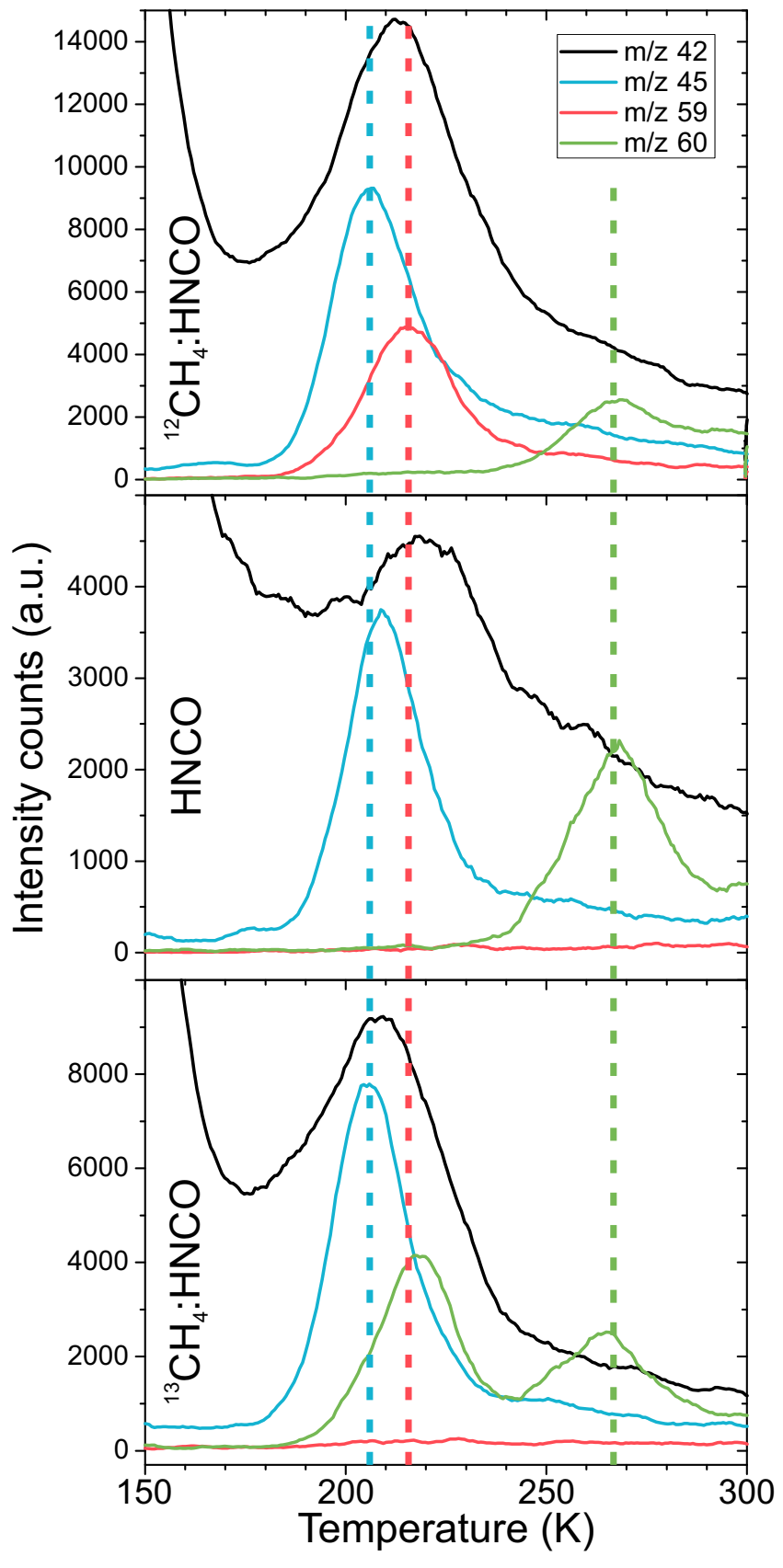

Figure 5. TPD traces of $\mathrm{m} / \mathrm{z} 42$ (black, NCO fragment of $\mathrm{HNCO}$ ), 45 (blue, $\mathrm{NH}_{2} \mathrm{CHO}$ ), 59 (red, $\mathrm{CH}_{3} \mathrm{C}(\mathrm{O}) \mathrm{NH}_{2}$ ) and 60 (green, $\mathrm{NH}_{2} \mathrm{C}(\mathrm{O}) \mathrm{NH}_{2}$ ) between 150 and $300 \mathrm{~K}$ of far-UV processed $\mathrm{HNCO}:{ }^{12} \mathrm{CH}_{4}$ (Exp. 1, top), pure HNCO (Exp. 2, middle) and $\mathrm{HNCO}:{ }^{13} \mathrm{CH}_{4}$ (Exp. 3, bottom) ice. Dashed lines indicate the desorption peaks of products.

$\mathrm{HNCO}$ to form the $\mathrm{OCN}^{-} \mathrm{NH}_{4}^{+}$complex (van Broekhuizen et al. 2004).

A feature in the wing of the $\mathrm{HNCO}$ peak at 2322 $\mathrm{cm}^{-1}$ indicates the formation of $\mathrm{CH}_{3} \mathrm{NCO}$ (Ligterink et al. 2017; Maté et al. 2017). At $\sim 1687 \mathrm{~cm}^{-1}$ another feature is visible. In far-UV processing of pure HNCO ice, it was identified as a combination of contributions of the $\mathrm{H}_{2} \mathrm{CO}$ and $\mathrm{NH}_{2} \mathrm{CHO} \mathrm{C}=\mathrm{O}$ stretch modes and $\mathrm{NH}$ bend-

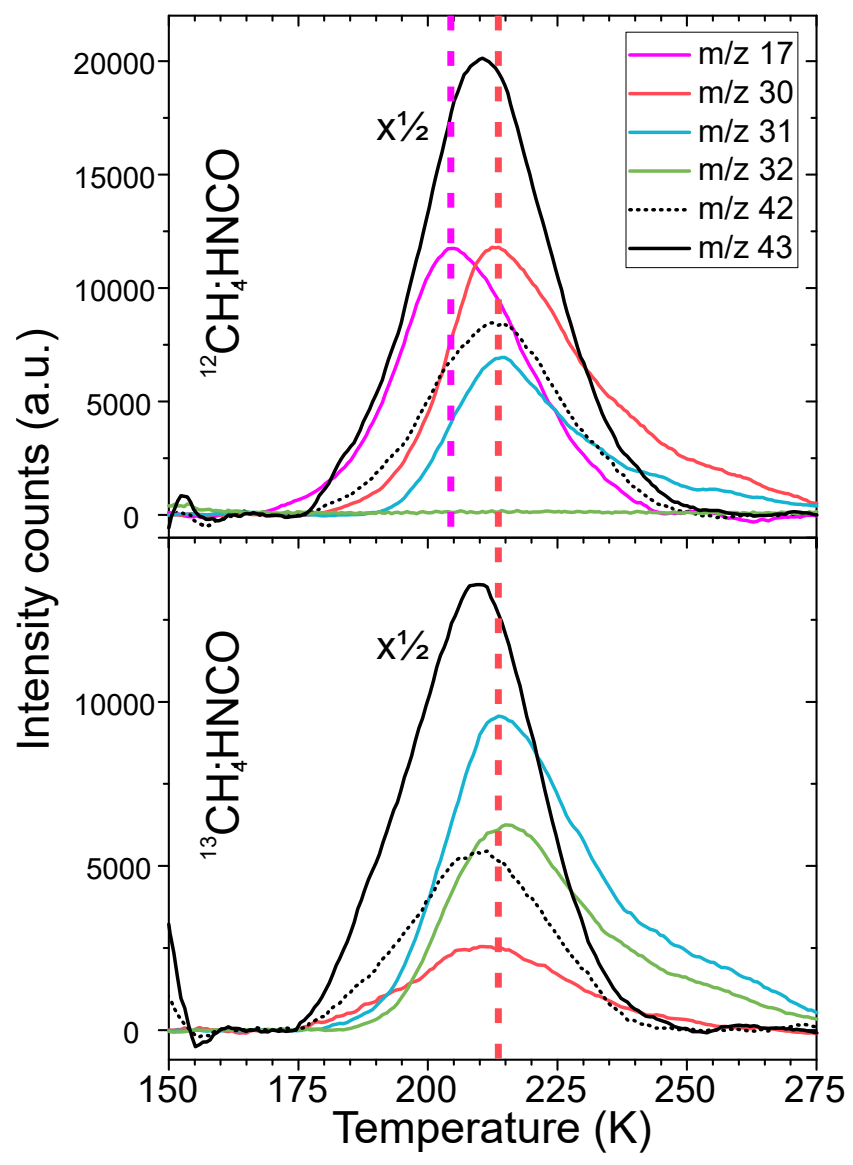

Figure 6. Baseline subtracted TPD traces of $\mathrm{m} / \mathrm{z} 17$ (purple), 30 (red), 31 (blue), 32 (green), 42 (black dashed) and 43 (black, scaled by factor $1 / 2$ ) of $\mathrm{HNCO}:{ }^{12} \mathrm{CH}_{4}$ (Exp. 1, top) and HNCO: ${ }^{13} \mathrm{CH}_{4}$ (Exp. 3, bottom) ice. The dashed purple line indicates the peak desorption temperature of $\mathrm{m} / \mathrm{z}, 17$ and the red dashed line indicates the peak desorption temperature of $m / z 30$, 31 and 32 .

ing modes of $\mathrm{NH}_{2} \mathrm{C}(\mathrm{O}) \mathrm{NH}_{2}$ (Raunier et al. 2004). These species likely contribute to this feature, but can not be distinguished. More complex amides, such as $\mathrm{CH}_{3} \mathrm{NHCHO}$ and $\mathrm{CH}_{3} \mathrm{C}(\mathrm{O}) \mathrm{NH}_{2}$ should also have strong $\mathrm{C}=\mathrm{O}$ stretch modes that can contribute to this feature. Since other spectroscopic features, characteristic of complex amides, are not seen in the RAIR spectra, mass spectrometry must be used to identify these species. An overview of the identified products visible in the IR in Exp. 1 is given in Table 2.

\subsection{Identification of the primary amides}

Figure 5 shows the TPD traces between 150 and $300 \mathrm{~K}$ of the main masses of the simplest, or primary, amides that can be formed from $\mathrm{HNCO}: \mathrm{CH}_{4}$ ice mixtures. These masses are $m / z 45$ for $\mathrm{NH}_{2} \mathrm{CHO}, m / z 59$ for either $\mathrm{CH}_{3} \mathrm{C}(\mathrm{O}) \mathrm{NH}_{2}$ or $\mathrm{CH}_{3} \mathrm{NHCHO}$ and $m / z, 60$ for $\mathrm{NH}_{2} \mathrm{CONH}_{2}$. The secondary mass channel of HNCO, $\mathrm{m} / \mathrm{z} 42$, is included as well to trace HNCO. The panels show from top to bottom the results of the UV irradiation of ${ }^{12} \mathrm{CH}_{4}: \mathrm{HNCO}, \mathrm{HNCO}$ and ${ }^{13} \mathrm{CH}_{4}$ :HNCO (Exps. 1-3, respectively).

In each of the panels a prominent trailing slope of $\mathrm{m} / \mathrm{z}$ 


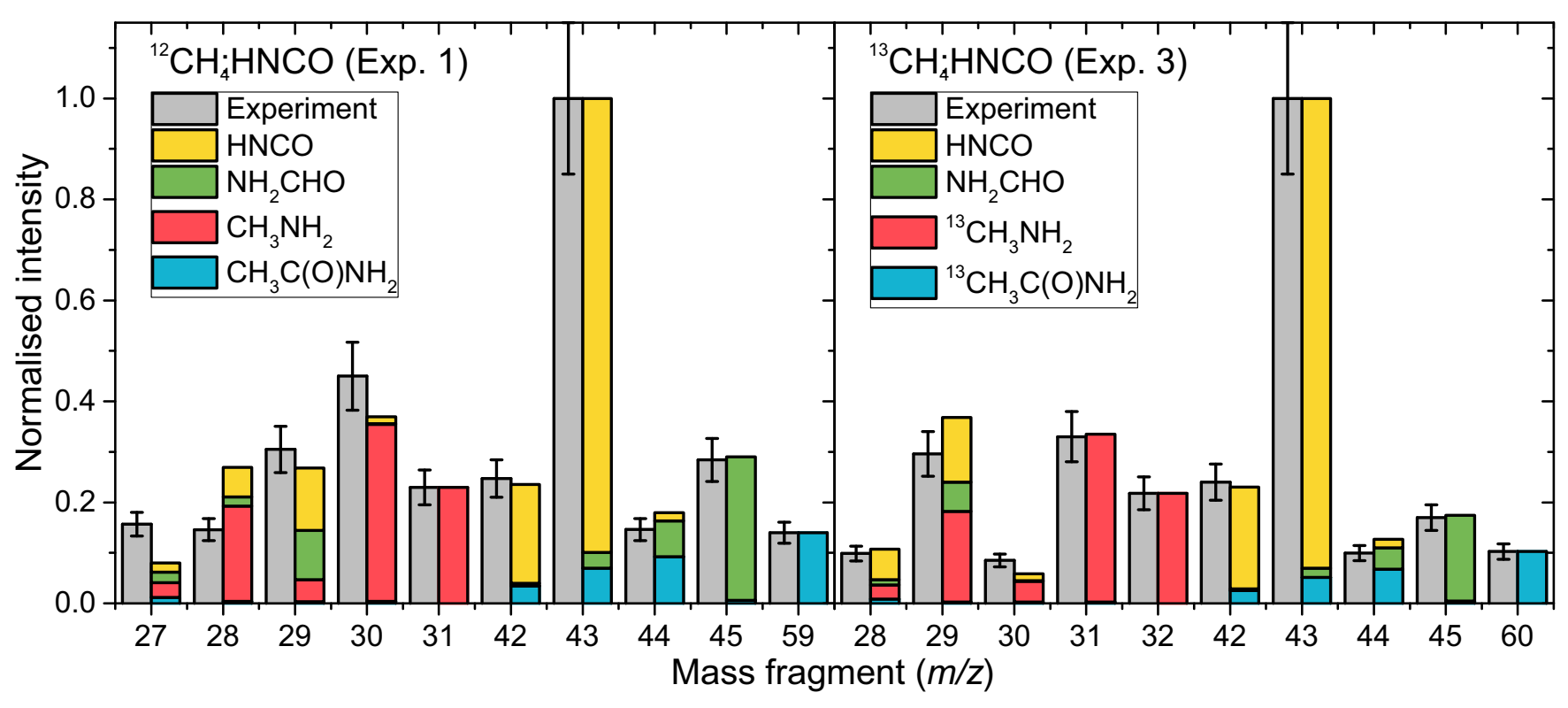

Figure 7. The fragments at $m / z 60 / 59,45,44,43,42,32 / 31,31 / 30,30 / 29,29 / 28$ and $28 / 27$ found desorbing around $210 \mathrm{~K}$ in experiments 1 and 3 (black), fitted with the combined fragmentation patterns of ${ }^{12 / 13}$ acetamide (blue), ${ }^{12 / 13}$ methylamine (red), formamide (green) and HNCO (yellow). Note that intensity ratios do not directly reflect abundance ratios.

42 between 150 and $300 \mathrm{~K}$, with a superimposed desorption feature at $\sim 210 \mathrm{~K}$ is seen. The trailing slope is due to residual gas of the main HNCO desorption peak at 130 K, see Fig. A3 in Appendix A. The desorption feature is caused by the thermal decomposition of the $\mathrm{OCN}^{-} \mathrm{NH}_{4}^{+}$(or another cation) salt complex and subsequent desorption of HNCO.

Three desorption peaks of $\mathrm{m} / \mathrm{z} 45,59$ and 60 are visible at $\sim 205, \sim 215$ and $\sim 265 \mathrm{~K}$, respectively. Moreover, $\mathrm{m} / \mathrm{z}, 45$ and 60 show up in all panels, including the irradiated pure HNCO ice, and therefore must be photoproducts directly resulting from $\mathrm{HNCO}$. The desorption peak of $\mathrm{m} / \mathrm{z} 45$ at $205 \mathrm{~K}$ matches the desorption temperature of pure $\mathrm{NH}_{2} \mathrm{CHO}$ at $210 \mathrm{~K}$ and is therefore assigned to this molecule. The position of the $\mathrm{m} / \mathrm{z}, 60$ desorption peak is consistent with TPD traces of $\mathrm{NH}_{2} \mathrm{C}(\mathrm{O}) \mathrm{NH}_{2}$ obtained by Förstel et al. (2016) and is identified accordingly. Both identifications are consistent with results of pure $\mathrm{HNCO}$ irradiation by Raunier et al. (2004).

The $m / z 59$ feature is the result of a reaction between $\mathrm{CH}_{4}$ and $\mathrm{HNCO}$ related fragments, as can be inferred from its non-presence in the pure $\mathrm{HNCO}$ experiment and $1 \mathrm{amu}$ mass shift to $\mathrm{m} / \mathrm{z}, 60$ in the ${ }^{13} \mathrm{CH}_{4}: \mathrm{HNCO}$ experiment. This product can either be $\mathrm{CH}_{3} \mathrm{NHCHO}$ or $\mathrm{CH}_{3} \mathrm{C}(\mathrm{O}) \mathrm{NH}_{2}$. Other isomers like acetaldoxime $\left(\mathrm{CH}_{3} \mathrm{CHNOH}\right)$ and nitrosoethane $\left(\mathrm{CH}_{3} \mathrm{CH}_{2} \mathrm{NO}\right)$ are deemed unlikely to be responsible for the $\mathrm{m} / \mathrm{z} 59$ feature, due to the many fragmentation and reaction steps that need to be invoked to form these products. The desorption peak of $\mathrm{m} / \mathrm{z} 59$ at $215 \mathrm{~K}$ is close to the desorption temperature of pure $\mathrm{CH}_{3} \mathrm{C}(\mathrm{O}) \mathrm{NH}_{2}$ at $219 \mathrm{~K}$, as shown in Fig. 3. Trapping of $\mathrm{CH}_{3} \mathrm{NHCHO}$ in the ice contents (mainly $\mathrm{OCN}^{-} \mathrm{NH}_{4}^{+}$and $\mathrm{NH}_{2} \mathrm{CHO}$ ) and thus shifting to a higher desorption temperature is ruled out, due to the relatively volatile nature of $\mathrm{CH}_{3} \mathrm{NHCHO}$. If this were the case, one would expect it to desorb before or with $\mathrm{NH}_{2} \mathrm{CHO}$ and $\mathrm{OCN}^{-} \mathrm{NH}_{4}^{+}$, but a desorption at a higher temperature, as is the case here, is unlikely.

\subsection{Mass fragmentation pattern fit}

Further evidence for the identification of $\mathrm{CH}_{3} \mathrm{C}(\mathrm{O}) \mathrm{NH}_{2}$ can be found by fitting its mass fragmentation pattern. As shown in section 2.4 and Fig. $\mathrm{A} 2, \mathrm{CH}_{3} \mathrm{C}(\mathrm{O}) \mathrm{NH}_{2}$ has prominent fragmentation channels at $m / z, 44$ and 43 , while $\mathrm{CH}_{3} \mathrm{NHCHO}$ has channels into $m / z 30$ and 29. Interestingly, $m / z 30$ does show up prominently in the TPD trace around $220 \mathrm{~K}$, as does $m / z 31$, see Fig. 6. Both these masses are shifted to $m / z 31$ and 32 , respectively, in the ${ }^{13} \mathrm{CH}_{4}$ isotope experiment. The $\mathrm{m} / \mathrm{z} 30$ and 31 signals are unlikely to be from $\mathrm{CH}_{3} \mathrm{NHCHO}$, however. First, there is no fragment channel at $\mathrm{m} / z 31$ for $\mathrm{CH}_{3} \mathrm{NHCHO}$ (although $\mathrm{m} / \mathrm{z} 30$ and 31 do not necessarily have to be associated). Second, the $m / z 30 / 59$ ratio in the experiments is greater than 1 , while the $\mathrm{m} / \mathrm{z} 30 / 59$ ratio of pure $\mathrm{CH}_{3} \mathrm{NHCHO}$ is 0.21 . Therefore, these masses are most likely due to another species, presumably methylamine $\left(\mathrm{CH}_{3} \mathrm{NH}_{2}\right)$.

To strengthen this claim, the main masses desorbing around $200-220 \mathrm{~K}$ are fitted with the fragmentation patterns of $\mathrm{HNCO}, \mathrm{NH}_{2} \mathrm{CHO}, \mathrm{CH}_{3} \mathrm{NH}_{2}$ and $\mathrm{CH}_{3} \mathrm{C}(\mathrm{O}) \mathrm{NH}_{2}$ (see Table A1 in Appendix A for the fragmenation patterns of these molecules). These masses are integrated between 170 and $250 \mathrm{~K}$, and in sequence the four components are added to reproduce the experimental fragment patterns. Figure 7 shows the results of these fits for Exps. 1 and 3. The ratios between the fitted components $\mathrm{CH}_{3} \mathrm{NH}_{2}: \mathrm{HNCO}: \mathrm{NH}_{2} \mathrm{CHO}: \mathrm{CH}_{3} \mathrm{C}(\mathrm{O}) \mathrm{NH}_{2}$ are 28:43:17:12 for the ${ }^{12} \mathrm{C}$ experiment and 30:50:11:9 for the ${ }^{13} \mathrm{C}$ experiment.

The experimental mass patterns are reasonably well fitted with a combination of these four molecules, particularly 
in the isotope experiment. Small differences can still occur due to contributions of other species to $\mathrm{m} / z, 27,28,29$ and 30 , such as fragments originating from more complex molecules. This fit confirms the identification of $\mathrm{CH}_{3} \mathrm{C}(\mathrm{O}) \mathrm{NH}_{2}$ and makes it very likely that $\mathrm{CH}_{3} \mathrm{NH}_{2}$ is also formed in these experiments. In pure form $\mathrm{CH}_{3} \mathrm{NH}_{2}$ thermally desorbs at relatively low temperatures of $100-120 \mathrm{~K}$ (e.g. Chaabouni et al. 2018), while in these experiments it desorbs at $\sim 220 \mathrm{~K}$. Due to bulk ice release with HNCO it is unclear in the TPD traces if some $\mathrm{CH}_{3} \mathrm{NH}_{2}$ releases around $110 \mathrm{~K}$. The release of $\mathrm{CH}_{3} \mathrm{NH}_{2}$ around $220 \mathrm{~K}$ can be explained by the formation of an $\mathrm{OCN}^{-} \mathrm{CH}_{3} \mathrm{NH}_{3}^{+}$salt complex, which has a higher desorption temperature, similar to the $\mathrm{OCN}^{-} \mathrm{NH}_{4}^{+}$ complex. Reference data on the thermal decomposition of the $\mathrm{OCN}^{-} \mathrm{CH}_{3} \mathrm{NH}_{3}^{+}$complex is needed to confirm this. Different peak desorption temperatures between these two salts are explained by the fact that $\mathrm{CH}_{3} \mathrm{NH}_{2}$ is a stronger base than $\mathrm{NH}_{3}$ and therefore more thermal energy is required to dissociate this complex.

\subsection{Secondary amides and larger species}

Evidence for the formation of more complex species is seen, as shown in Fig. 8. Three features at $m / z 73,74$ and 88 are detected in the TPD traces of Exps. 1-3. The first feature of $\mathrm{m} / \mathrm{z}, 73$, desorbing at $\sim 220 \mathrm{~K}$, does not show up in the processed pure HNCO sample. In the ${ }^{13} \mathrm{CH}_{4}$ experiment the feature shifts to $m / z 75$, indicating that two ${ }^{13} \mathrm{CH}_{x}$ groups are part of this product. The $m / z 74$ feature, desorbing at $\sim 260 \mathrm{~K}$, also does not show up in the pure HNCO processed ice and shifts by one mass to $\mathrm{m} / z, 75$ in the ${ }^{13} \mathrm{CH}_{4}$ mixture. Therefore this product incorporates only one ${ }^{13} \mathrm{CH}_{x}$ group. $\mathrm{m} / \mathrm{z} 88$ is seen in all three the panels and desorbs around $250 \mathrm{~K}$. Since it is observed in the pure $\mathrm{HNCO}$ ice and no isotope shifts are seen, it likely results from two HNCO related intermediates.

We note that the low signal-to-noise ratio (compare to Figs. 5 and 6 ) limits the identification of molecules and therefore contributions of more than three species to these $m / z$ signals can not be ruled out. Also, desorption temperatures of candidate molecules are not available and matching fragmentation patterns is hindered due to the low signal and overlap in fragmentation channels of previously identified, more abundant, species. Nevertheless, some candidates can be suggested, especially when assuming these high mass species are derived from, or related to the first generation of amides. For the $\mathrm{m} / \mathrm{z} 73$ signal propionamide $\left(\mathrm{CH}_{3} \mathrm{CH}_{2} \mathrm{C}(\mathrm{O}) \mathrm{NH}_{2}\right)$, N-methylacetamide $\left(\mathrm{CH}_{3} \mathrm{NHCOCH}_{3}\right)$ and dimethylformamide $\left(\left(\mathrm{CH}_{3}\right)_{2} \mathrm{NCHO}\right)$ could be responsible. The latter two seem unlikely because $\mathrm{CH}_{3} \mathrm{NHCHO}$ is not detected in these mixtures. The fact that $\mathrm{CH}_{3} \mathrm{CH}_{3}$ is identified in the IR spectra of these experiments, favors the assignment as $\mathrm{CH}_{3} \mathrm{CH}_{2} \mathrm{C}(\mathrm{O}) \mathrm{NH}_{2}$. The two most likely options for $m / z, 74$ are methylcarbamide $\left(\mathrm{CH}_{3} \mathrm{NHC}(\mathrm{O}) \mathrm{NH}_{2}\right)$ and 2-amino acetamide $\left(\mathrm{NH}_{2} \mathrm{CH}_{2} \mathrm{C}(\mathrm{O}) \mathrm{NH}_{2}\right)$. Again, based on the non-detection of $\mathrm{CH}_{3} \mathrm{NHCHO}$, the latter molecule is the more likely candidate. Finally, for $\mathrm{m} / \mathrm{z}=88$ two options exist; oxamide $\left(\mathrm{NH}_{2}-\mathrm{C}(\mathrm{O})-\mathrm{C}(\mathrm{O})-\mathrm{NH}_{2}\right)$ or $1,2-$ hydrazinedicarboxaldehyde (CHO-NH-NH-CHO).

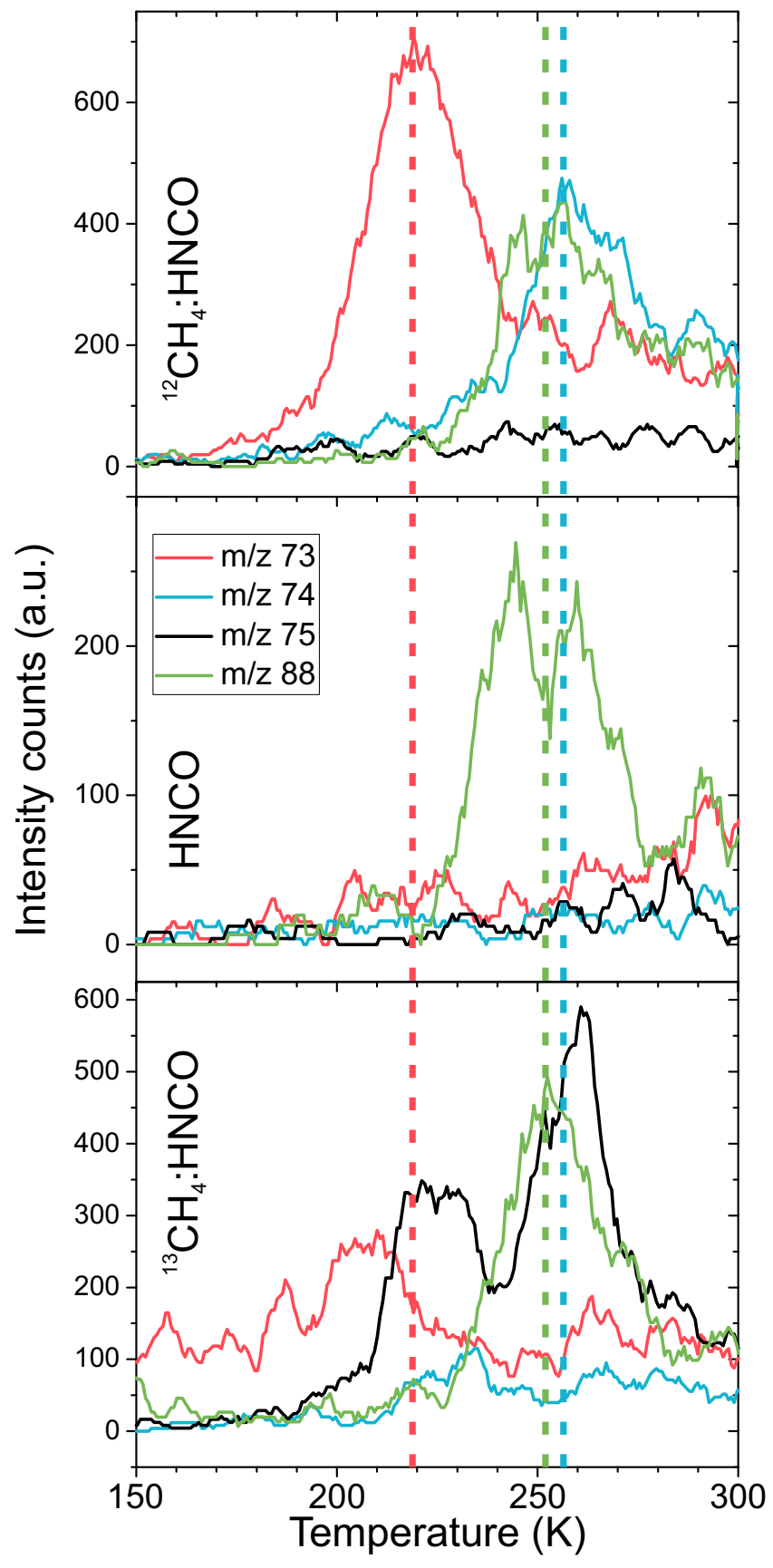

Figure 8. TPD of $m / z 73$ (red), 74 (blue), 75 (black) and 88 (green) between 150 and $300 \mathrm{~K}$ of UV processed HNCO: $:{ }^{12} \mathrm{CH}_{4}$ (top), $\mathrm{HNCO}$ (middle) and HNCO: ${ }^{13} \mathrm{CH}_{4}$ (bottom) ices. Dashed lines indicate the desorption peaks of various products.

\subsection{Comparison of experimental conditions}

Besides the experiments analysed thus far (Exps. 1-3), the influence of Lyman- $\alpha$ rich or poor emission (Exps. 1-4 \& 5-7) and the presence of a CO matrix (Exps. 6-7) on the chemistry has been investigated, see Table 1 . In this section trends and variations between all experiments (Exps. 1-7) are investigated based on a number of mass fragments, see Fig. 9. In this figure, ratios of prominent mass fragments are given with respect to $m / z 45\left(\mathrm{NH}_{2} \mathrm{CHO}\right)$. Here, $\mathrm{m} / \mathrm{z} 57$ 


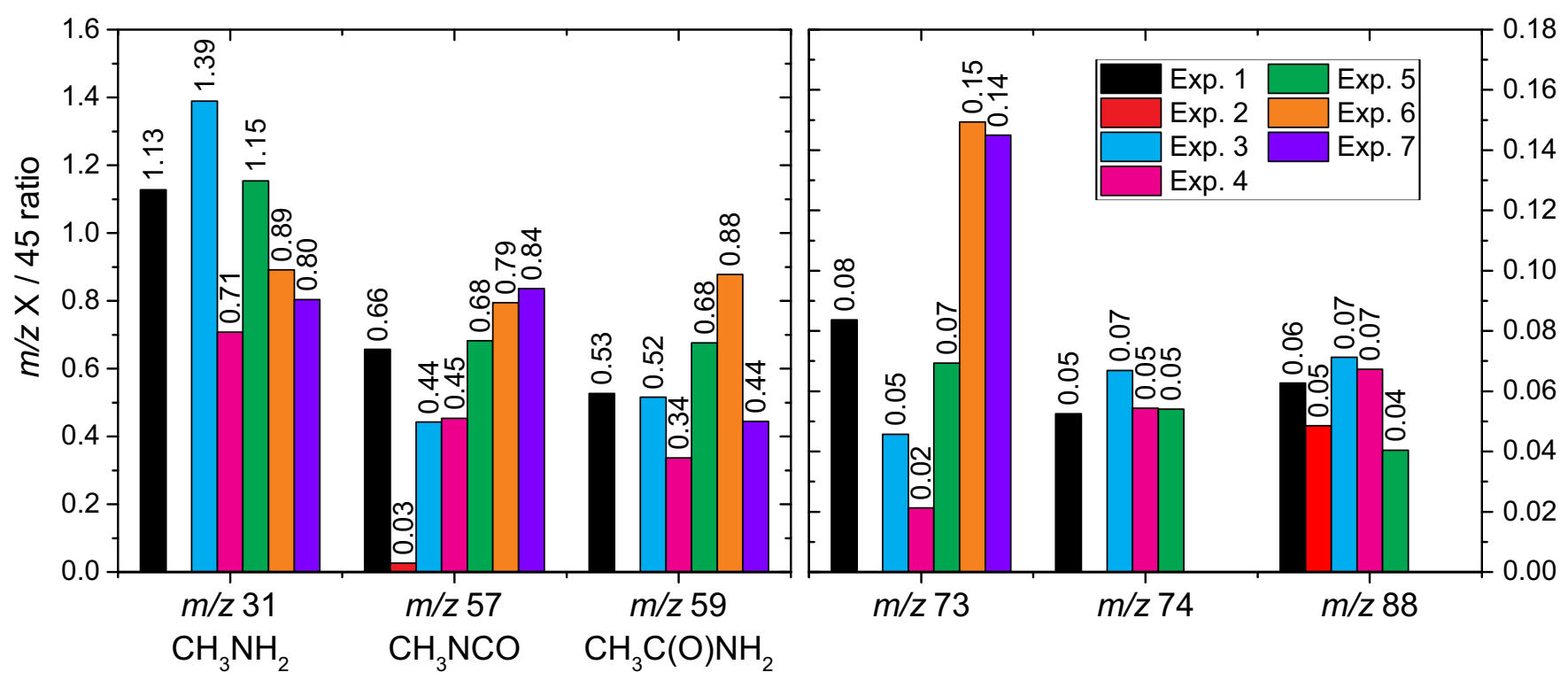

Figure 9. Comparison of mass fragment intensity ratios in all experiments. Note that intensity ratios do not reflect molecular abundance ratios.

$\left(\mathrm{CH}_{3} \mathrm{NCO}\right)$ is included, but note that this species co-desorbs below $150 \mathrm{~K}$, with HNCO. The experiments with the CO matrix (Exps. 6 and 7) are less reliable in tracing $m / z$ 31, because not desorption peaks, but rather desorption plateaus are seen for this mass. The same effect is observed for $\mathrm{m} / \mathrm{z}$ 30. Finally, results of the ${ }^{13} \mathrm{CH}_{4}$ experiment (Exp. 3) are included at the non-isotope masses presented in this figure.

From Fig. 9 it becomes clear that $\mathrm{CH}_{3} \mathrm{NH}_{2}, \mathrm{CH}_{3} \mathrm{NCO}$ and $\mathrm{CH}_{3} \mathrm{C}(\mathrm{O}) \mathrm{NH}_{2}$ are present in all experiments, masses $\mathrm{m} / \mathrm{z}$ 73,74 and 88 in most and intensity ratios are relatively similar. The presence of Lyman- $\alpha$ (Exps. $5-7$ ) is not a prerequisite for the formation of these species. The CO matrix (Exps. 6 and 7 ) does hinder the formation of the products associated with $m / z 74$ and 88 , however. Since $\mathrm{CH}_{4}$ mainly absorbs far-UV radiation around the Lyman- $\alpha$ transition (Cruz-Diaz et al. 2014), it either implies that the small amount of available high-energy radiation is enough to make a sufficient amount of $\mathrm{CH}_{3}$ radicals, or this radical is formed efficiently by $\mathrm{H}$-abstraction reactions with other atoms and molecules, such as N and NH (see also discussion in Bossa et al. 2015). The experiments conducted in a CO matrix hint that not hydrogenation, but radical recombination reactions are responsible for forming the products. The $\mathrm{H}$-atoms produced in the photodestruction of the precursor species are thermalised by the interaction with the $\mathrm{CO}$ matrix and thus have no, or limited, excess energy. Since hydrogenation with non-energetic $\mathrm{H}$-atoms has been shown not to be able to hydrogenate $\mathrm{HNCO}$ into $\mathrm{NH}_{2} \mathrm{CHO}$ (Noble et al. 2015) at low $(10-17 \mathrm{~K})$ temperatures, hydrogenation of HNCO can be ruled out in these experiments. Because roughly similar product ratios are found in experiments with and without a $\mathrm{CO}$ matrix, energetic $\mathrm{H}$-atom addition to $\mathrm{HNCO}$ is unlikely to be the mechanism to form $\mathrm{NH}_{2} \mathrm{CHO}$ and intermediate radicals. Also, IR spectra show no formation of products during irradiation, but do show a decrease in the HNCO and $\mathrm{CH}_{4}$ column. Upon warm-up of the ice, formation of products is seen, specifically above $30 \mathrm{~K}$ when CO desorbs, see Fig. 10 .

\section{INTERSTELLAR OBSERVATIONS}

Detections of $\mathrm{CH}_{3} \mathrm{C}(\mathrm{O}) \mathrm{NH}_{2}$ and a tentative identification of $\mathrm{CH}_{3} \mathrm{NHCHO}$ have been made towards high-mass Young Stellar Objects (YSOs), specifically Sgr B2 and Orion KL (Hollis et al. 2006; Halfen et al. 2011; Cernicharo et al. 2016; Belloche et al. 2017). Detections towards low-mass protostars are lacking so far, and this may be due to physical differences between high- and low-mass sources caused by, for example, dust grain temperatures and radiation fields. IRAS 16293-2422 (hereafter IRAS 16293) is such a low-mass protostellar source, consisting of two protostars A and B. Due to its relative close proximity at $120 \mathrm{pc}$ and high luminosity of $21 L_{\odot}$ (Jørgensen et al. 2016) this has been a long time favourite low-mass object to study complex chemistry (e.g. Cazaux et al. 2003). For this reason, we have searched for $\mathrm{CH}_{3} \mathrm{C}(\mathrm{O}) \mathrm{NH}_{2}$ and $\mathrm{CH}_{3} \mathrm{NHCHO}$ towards the protostar IRAS 16293B.

\subsection{Observations and analysis}

Interferometric observations of the Atacama Large Millimeter/submillimeter Array (ALMA) are used for this search. Specifically, data from the Protostellar Interferometric Line Survey (PILS, Jørgensen et al. 2016), supplemented by data from Taquet et al. (subm., project-id: 2016.1.01150.S). are used. In short, these data cover large parts of the spectral ranges in ALMA Bands 6 and 7 at a spectral resolution of $0.2 \mathrm{~km} \mathrm{~s}^{-1}$ and high $\mathrm{rms}$ sensitivity of $0.5-5 \mathrm{mJy}^{-1}$ beam $^{-1}$ $\mathrm{km} \mathrm{s}^{-1}$. The observations have a circular restoring beam of $0 . \prime 5$, which ensures that the hot corino around IRAS 16293B 


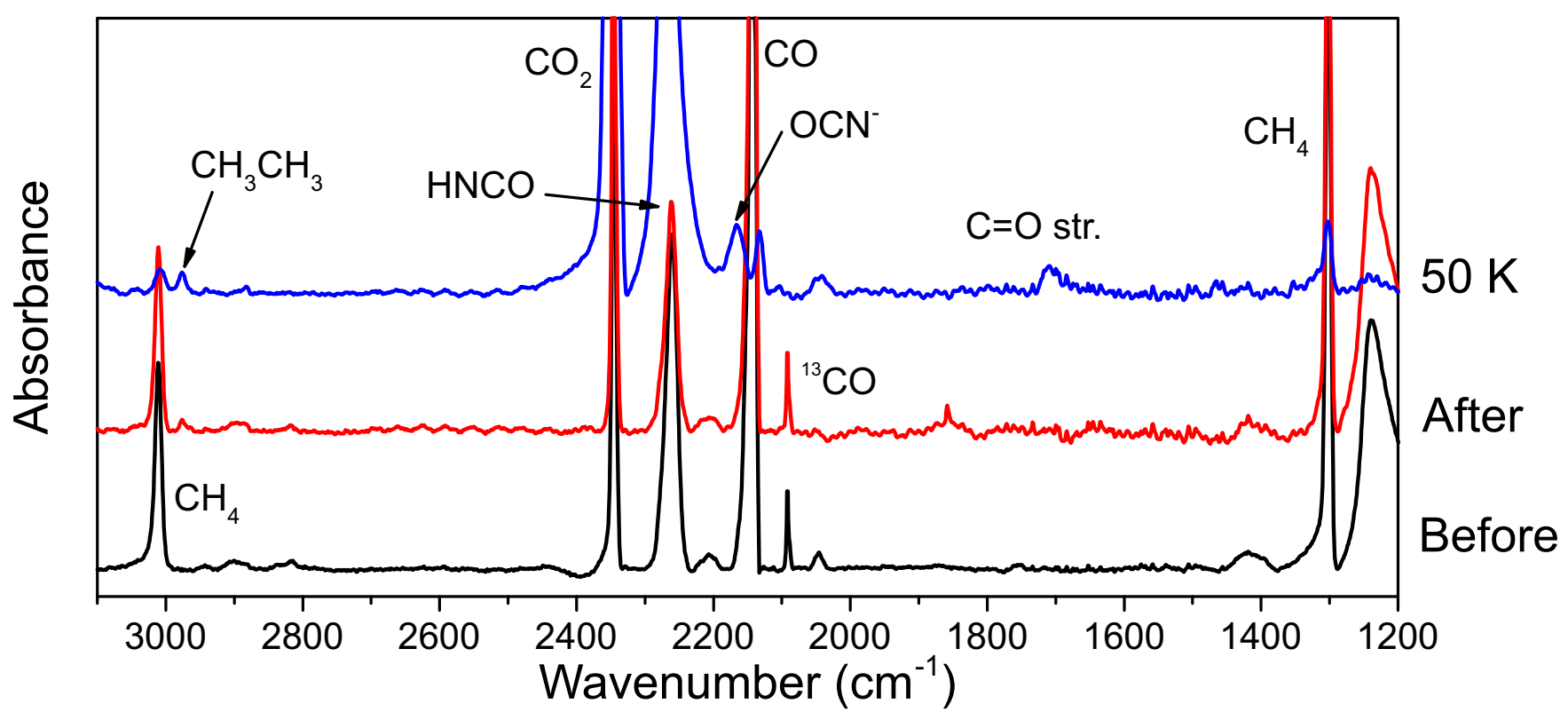

Figure 10. Spectra of the $\mathrm{CH}_{4}: \mathrm{HNCO} \mathrm{CO}$ experiment (Exp. 7), before irradiation (black), after irradiation (red) and after heating to $50 \mathrm{~K}$ (blue).
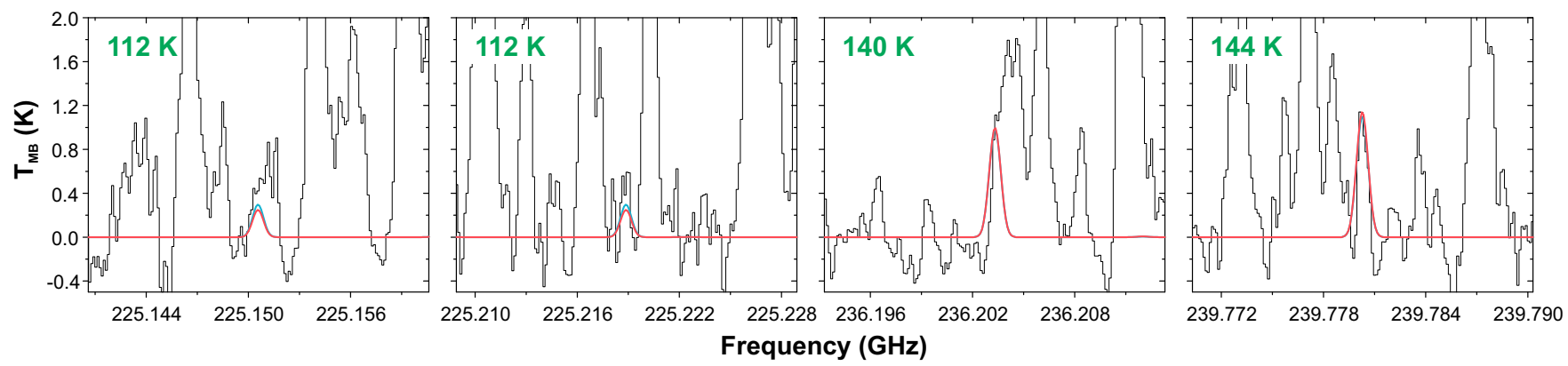

Figure 11. Spectrum of IRAS 16293-2422B (black) with the synthetic spectrum of $\mathrm{CH}_{3} \mathrm{C}(\mathrm{O}) \mathrm{NH}_{2}$ at $T_{\mathrm{ex}}=100 \mathrm{~K}$ (blue) and $300 \mathrm{~K}$ (red) overplotted. On the y-axis, the intensity of the measured rotational lines is indicated by the main beam temperature $\left(T_{\mathrm{MB}}\right)$ in Kelvin. The upper state energy of each line is given in green.

(diameter of $\sim 160 \mathrm{AU}$ ) can be spatially resolved. A position located at 1 beam size offset with respect to the peak dust continuum emission of source B is used for the analysis. This region is characterised by narrow rotational lines of $\sim 1 \mathrm{~km} \mathrm{~s}^{-1}$ and therefore line-blending is minimized (e.g. Coutens et al. 2016; Lykke et al. 2017).

The rotational spectroscopic data of the lowest three vibrational states of $\mathrm{CH}_{3} \mathrm{C}(\mathrm{O}) \mathrm{NH}_{2}$ are provided by Ilyushin et al. (2004) and the rotational spectroscopy of $\mathrm{CH}_{3} \mathrm{NHCHO}$ is given by Belloche et al. (2017), respectively. The Jet Propulsion Laboratory ( $\mathrm{JPL}^{2}$ ) catalog for molecular spectroscopy (Pickett et al. 1998) and Cologne Database for Molecular Spectroscopy (CDMS; Müller et al. 2001, 2005) are used to check for contaminating lines. The CASSIS line analysis software ${ }^{3}$ is used to analyse the spectra.

\footnotetext{
2 http://spec.jpl.nasa.gov

3 http://cassis.irap.omp.eu/
}

Upon detection of rotational lines belonging to these molecules, their column density is derived by making a grid of synthetic spectra, assuming Local Thermodynamic Equilibrium (LTE), and determining the best fit model based on the minimum $\chi^{2}$. The column density $(N)$ is scanned between $5 \times 10^{14}$ and $5 \times 10^{15} \mathrm{~cm}^{-2}$ in steps of $1 \times 10^{14} \mathrm{~cm}^{-2}$, while $T_{\text {ex }}$ is fixed at either 100 or $300 \mathrm{~K}$, the excitation temperature at which most complex molecules are found in the PILS data. Other input parameters for the synthetic spectra are kept constant, such as the line width at $1 \mathrm{~km} \mathrm{~s}^{-1}$ and $V_{\text {lsr }}$ at $2.7 \mathrm{~km} \mathrm{~s}^{-1}$.

\subsection{Results}

In the observed spectra, two unblended and two partially blended lines are identified belonging to $\mathrm{CH}_{3} \mathrm{C}(\mathrm{O}) \mathrm{NH}_{2}$, see Fig. 11, making for a tentative identification of the molecule. The parameters of the detected lines, and molecules they 
Table 3. Observed $\mathrm{CH}_{3} \mathrm{C}(\mathrm{O}) \mathrm{NH}_{2}$ and $\mathrm{CH}_{3} \mathrm{NHCHO}$ abundances with respect to $\mathrm{HNCO}, \mathrm{NH}_{2} \mathrm{CHO}, \mathrm{CH}_{3} \mathrm{NCO}$, and $\mathrm{H}_{2}$ towards IRAS 16293-2422B.

\begin{tabular}{lll}
\hline \hline Reference & $\mathrm{CH}_{3} \mathrm{C}(\mathrm{O}) \mathrm{NH}_{3}$ & $\mathrm{CH}_{3} \mathrm{NHCHO}$ \\
\hline$/ \mathrm{HNCO}$ & $\sim 0.03-0.08$ & $\leq 0.03$ \\
$/ \mathrm{NH}_{2} \mathrm{CHO}$ & $\sim 0.09-0.25$ & $\leq 0.10$ \\
$/ \mathrm{CH}_{3} \mathrm{NCO}$ & $\sim 0.23-0.83$ & $\leq 0.25$ \\
$/ \mathrm{H}_{2}$ & $\leq 2.10 \times 10^{-10}$ & $\leq 8.3 \times 10^{-11}$ \\
\hline
\end{tabular}

are blended with, are presented in Table B1 in Appendix B. The lines are low in intensity and therefore quite sensitive to baseline fluctuations. At the same time, their upper state energies only cover a small region of $E_{\text {up }}=112-141 \mathrm{~K}$. These issues make it difficult to properly fit a synthetic spectrum and derive an excitation temperature. We therefore run our grid of synthetic spectra at fixed temperatures of 100 and $300 \mathrm{~K}$, similar to Coutens et al. (2016) and Ligterink et al. (2017). The best-fit column densities are found to be $9 \times 10^{14}$ and $2.5 \times 10^{15} \mathrm{~cm}^{-2}$ for $T_{\mathrm{ex}}=100$ and $300 \mathrm{~K}$, respectively (Fig. 11).

No $\mathrm{CH}_{3} \mathrm{NHCHO}$ lines are identified and therefore an upper limit column density is provided. From line-free regions where $\mathrm{CH}_{3} \mathrm{NHCHO}$ lines are expected, the column density is determined to be $\leq 1 \times 10^{15} \mathrm{~cm}^{-2}$ at $T_{\mathrm{ex}}$ of $100-300 \mathrm{~K}$.

The comparison between both species gives $\left[\mathrm{CH}_{3} \mathrm{NHCHO}\right] /\left[\mathrm{CH}_{3} \mathrm{C}(\mathrm{O}) \mathrm{NH}_{2}\right] \leq 0.4-1.1$ in IRAS 16293B, consistent with the ratio of 0.7 derived towards Sgr B2(N2) (Belloche et al. 2017). For both species column density ratios are determined with respect to relevant molecules. Comparisons are made with $\mathrm{HNCO}\left(3 \times 10^{16} \mathrm{~cm}^{-2}\right), \mathrm{NH}_{2} \mathrm{CHO}$ $\left(1 \times 10^{16} \mathrm{~cm}^{-2}\right.$, Coutens et al. 2016), $\mathrm{CH}_{3} \mathrm{NCO}\left(3-4 \times 10^{15}\right.$ $\mathrm{cm}^{-2}$, Ligterink et al. 2017) and $\mathrm{H}_{2}\left(\geq 1.2 \times 10^{25} \mathrm{~cm}^{-2}\right.$, Jørgensen et al. 2016). The column densities of the first four molecules have been determined towards the 1 beam offset position towards source $\mathrm{B}$. The $\mathrm{H}_{2}$ column density is determined from dust continuum emission (Jørgensen et al. 2016), which is optically thick at the 1 beam offset position and thus a lower limit. Abundances for the molecules are given in Table 3 .

\subsection{Experimental and observational abundance comparison}

TPD data from the experiments yield ratios between molecules that can be directly compared to observed gasphase ratios and make it possible to directly link laboratory with interstellar chemical processes. Strictly speaking, experiments and observations cannot be compared directly due to differences in, for example, irradiation fluxes, timescales and exact ice composition. Nevertheless, the experiments do provide insight in abundance ratio trends.Equation 2 is used to determine the experimental gas-phase ratios for $\mathrm{CH}_{3} \mathrm{C}(\mathrm{O}) \mathrm{NH}_{2}$ and $\mathrm{CH}_{3} \mathrm{NH}_{2}$ relative to $\mathrm{NH}_{2} \mathrm{CHO}$. The $I_{59 \text {,acetamide }} / I_{45 \text {, formamide }}$ ratio is taken as 0.50 , while that

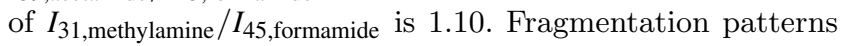
give $\phi_{59 \text {,acetamide }}=0.29, \phi_{45 \text {,formamide }}=0.41$ and $\phi_{31 \text {,methylamine }}$ $=0.26$. To our knowledge, total electron impact absorp-

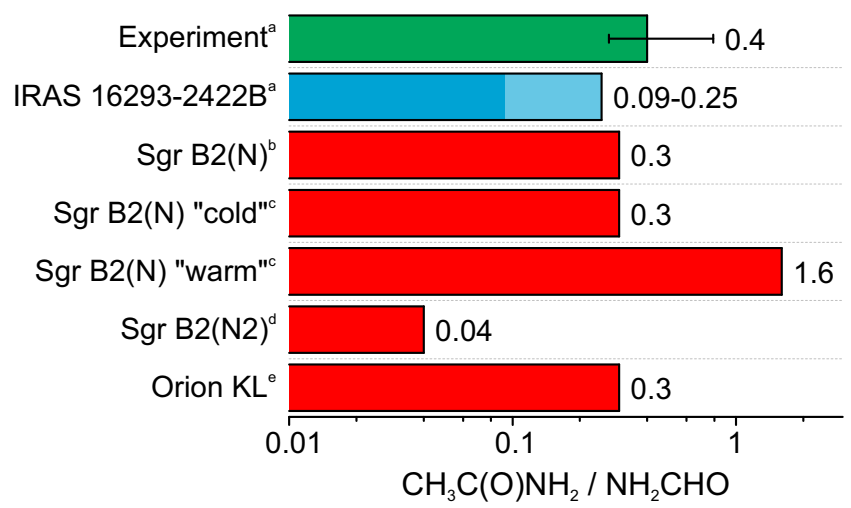

Figure 12. $\mathrm{CH}_{3} \mathrm{C}(\mathrm{O}) \mathrm{NH}_{2}$ over $\mathrm{NH}_{2} \mathrm{CHO}$ abundance ratio as found in Exp. 1 of this work compared with ratios derived in observational studies. ${ }^{a}$ This work; ${ }^{b}$ Hollis et al. (2006); ${ }^{c}$ Halfen et al. (2011); ${ }^{d}$ Belloche et al. (2017); ${ }^{e}$ Cernicharo et al. (2016).

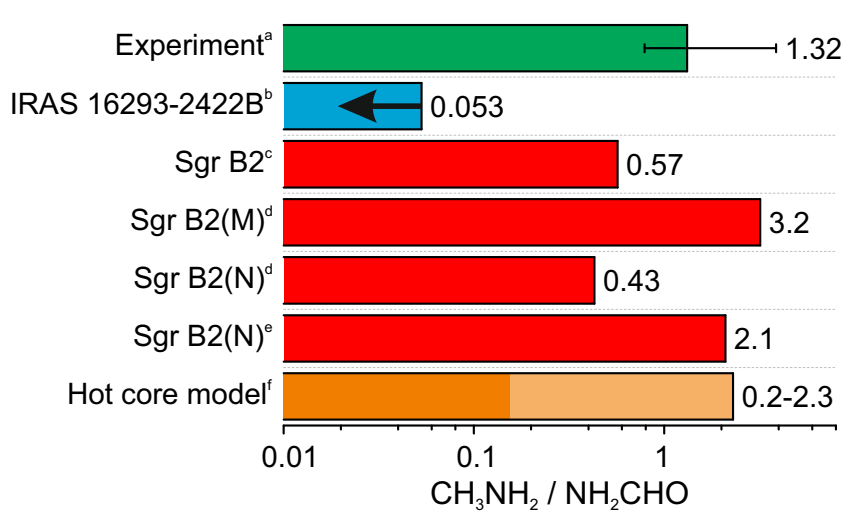

Figure 13. $\mathrm{CH}_{3} \mathrm{NH}_{2}$ over $\mathrm{NH}_{2} \mathrm{CHO}$ abundance ratio as found in Exp. 1 of this work compared with ratios derived in observational studies and calculated in models. ${ }^{a}$ This work; ${ }^{b}$ Ligterink et al. 2018 subm.; ${ }^{c}$ Turner (1991); ${ }^{d}$ Belloche et al. (2013); ${ }^{e}$ Neill et al. (2014); ${ }^{f}$ Garrod (2013).

tion cross sections have not experimentally been determined for any of these species. The theoretical absorption cross section for $\mathrm{NH}_{2} \mathrm{CHO}$ is calculated to be $5.595 \AA^{2}$ (Gupta et al. 2014), but calculated values for $\mathrm{CH}_{3} \mathrm{C}(\mathrm{O}) \mathrm{NH}_{2}$ and $\mathrm{CH}_{3} \mathrm{NH}_{2}$ are not available. Therefore we adopt the calculated cross sections of $\mathrm{CH}_{3} \mathrm{NHCHO}\left(10.063 \AA^{2}\right)$ and propylamine $\left(\mathrm{CH}_{3} \mathrm{CH}_{2} \mathrm{CH}_{2} \mathrm{NH}_{2}, 7.569 \AA^{2}\right)$ from Gupta et al. (2014) with a generous error bar of $\pm 5 \AA^{2}$. Based on these numbers, ratios are calculated to be $\left[\mathrm{CH}_{3} \mathrm{C}(\mathrm{O}) \mathrm{NH}_{2}\right]$ $/\left[\mathrm{NH}_{2} \mathrm{CHO}\right]=0.4_{-0.14}^{+0.39}$ and $\left[\mathrm{CH}_{3} \mathrm{NH}_{2}\right] /\left[\mathrm{NH}_{2} \mathrm{CHO}\right]=$ $1.32_{-0.53}^{+2.56}$.

The experimentally derived $\mathrm{CH}_{3} \mathrm{C}(\mathrm{O}) \mathrm{NH}_{2}$ abundance is compared with observational ratios towards Sgr B2, Orion KL and IRAS 16293B in Fig. 12. The observational data are a mix of single dish (Hollis et al. 2006; Halfen et al. 2011) and interferometric ALMA (this work, Cernicharo et al. 2016; Belloche et al. 2017) data. When comparing with single dish data, one needs to be aware that beam dilution effects can strongly affect column densities and thus molecule ratios. In general the $\left[\mathrm{CH}_{3} \mathrm{C}(\mathrm{O}) \mathrm{NH}_{2}\right] /\left[\mathrm{NH}_{2} \mathrm{CHO}\right]$ ratios are found to 
be similar within a factor of a few, including the tentative detection towards IRAS 16293B. A clear outlier is the ratio of 0.04 derived for Sgr B2(N2) (Belloche et al. 2017). The overall match between observational and experimental data hints that similar ice processes on interstellar dust grains and in laboratory ices are responsible for forming $\mathrm{CH}_{3} \mathrm{C}(\mathrm{O}) \mathrm{NH}_{2}$ and $\mathrm{NH}_{2} \mathrm{CHO}$ and thus both species have a common chemical origin. Furthermore, the mechanism that is at play is not significantly affected by the colder and radiation poorer conditions of IRAS 16293B.

In Fig. 13, the $\left[\mathrm{CH}_{3} \mathrm{NH}_{2}\right] /\left[\mathrm{NH}_{2} \mathrm{CHO}\right]$ ratios are shown for the experimental results, observational data towards Sgr B2 (Turner 1991; Belloche et al. 2013; Neill et al. 2014) and IRAS 16293B (Ligterink et al. subm) and various hot core models by Garrod (2013). In general, a ratio of $\sim 1$ is found, except for the abundance towards the low-mass protostar, which has at least an order of magnitude lower abundance. Ligterink et al. (subm) indicates that the difference in low- and high-mass hot cores may be caused by differences in physical conditions, such as grain temperatures and intensity of the radiation field. The experimental conditions mimic the physical conditions of high-mass hot cores, in particular the surface temperature of $20 \mathrm{~K}$. Higher temperatures increase the mobility of radicals and result in loss of $\mathrm{H}$ atoms by desorption or $\mathrm{H}_{2}$ formation, thus limiting the back reaction after a hydrogen bond dissociation. The experiments thus hint that relatively warm conditions on interstellar dust grains are favourable for $\mathrm{CH}_{3} \mathrm{NH}_{2}$ formation.

\section{DISCUSSION}

Based on the experimental and observational data obtained in the previous sections, possible reaction pathways to the various products can be identified. For the amides it seems unlikely that hydrogenation reactions with energetic $\mathrm{H}$ atoms of $\mathrm{HNCO}$ lead to $\mathrm{NH}_{2} \mathrm{CHO}$ or intermediate radicals (i.e. $\mathrm{NH}_{2} \mathrm{CO}$ and $\mathrm{NHCHO}$ ). The formation of the amides is therefore explained by non-energetic radical recombination reactions of $\mathrm{NH}_{2}$. Energetic radicals, produced by far-UV dissociation of molecules, are not a prerequisite, as inferred from the CO matrix experiments, where these radicals will quickly thermalise.

$\mathrm{NH}_{2}+\mathrm{HCO} \rightarrow \mathrm{NH}_{2} \mathrm{CHO}$

$\mathrm{NH}_{2}+\mathrm{CO} \rightarrow \mathrm{NH}_{2} \mathrm{CO}$

$\mathrm{NH}_{2} \mathrm{CO}+\mathrm{CH}_{3} \rightarrow \mathrm{CH}_{3} \mathrm{C}(\mathrm{O}) \mathrm{NH}_{2}$

$$
\mathrm{NH}_{2} \mathrm{CO}+\mathrm{NH}_{2} \rightarrow \mathrm{NH}_{2} \mathrm{C}(\mathrm{O}) \mathrm{NH}_{2}
$$

Equation 3 is a formation pathway identified by Jones et al. (2011). For the formation of larger amides the carbamoyl radical $\left(\mathrm{NH}_{2} \mathrm{CO}\right)$ could be an important intermediate, as was suggested by Agarwal et al. (1985). However, the formation of $\mathrm{CH}_{3} \mathrm{C}(\mathrm{O}) \mathrm{NH}_{2}$ via $\mathrm{CH}_{3}+\mathrm{CO} \rightarrow \mathrm{CH}_{3} \mathrm{CO}$ followed by addition of the $\mathrm{NH}_{2}$ radical can not be ruled out, but is less likely due to the non-detection of acetaldehyde $\left(\mathrm{CH}_{3} \mathrm{CHO}\right)$ in these experiments.
The non-detection of $\mathrm{CH}_{3} \mathrm{NHCHO}$ has various implications for chemical pathways. It indicates that hydrogenation of $\mathrm{CH}_{3} \mathrm{NCO}$, an abundantly formed molecule in the ices investigated in this work, does not result in the formation of $\mathrm{CH}_{3} \mathrm{NHCHO}$. Hydrogenation experiments of pure $\mathrm{CH}_{3} \mathrm{NCO}$ have to be performed to confirm this. For other pathways, such as $\mathrm{CH}_{3}+\mathrm{NHCHO}$ or $\mathrm{CH}_{3}+\mathrm{CHO}$ radical addition, the required radicals seem not to be formed in sufficient amounts, easily destroyed or consumed to form other products. If $\mathrm{HNCHO}$ is formed in a similar radical addition reaction as $\mathrm{NH}_{2} \mathrm{CO}$ (i.e. $\mathrm{NH}+\mathrm{CHO}$ ), reduction or hydrogenation reactions can result in $\mathrm{HNCO}$ and $\mathrm{NH}_{2} \mathrm{CHO}$ formation. Since these reactions are likely to occur for the $\mathrm{NH}_{2} \mathrm{CO}$ radical as well, this does raise the question how $\mathrm{NHCHO}$ and $\mathrm{NH}_{2} \mathrm{CO}$ differ in terms of stability and reactivity. Further research into the behaviour of these radicals is of interest to understand the formation of amides in interstellar ices. Analysis of a TPD trace of $m / z, 59$ in Bossa et al. (2012, their Fig. 3) shows that peak desorption occurs just under $200 \mathrm{~K}$. This is between the peak desorption temperatures of $\mathrm{CH}_{3} \mathrm{NHCHO}$ and $\mathrm{CH}_{3} \mathrm{C}(\mathrm{O}) \mathrm{NH}_{2}$, but could mean that $\mathrm{CH}_{3} \mathrm{NHCHO}$ is indeed formed and co-desorbs with $\mathrm{NH}_{2} \mathrm{CHO}$. Therefore, an ice formation route of $\mathrm{CH}_{3} \mathrm{NHCHO}$ via $\mathrm{CH}_{3} \mathrm{NH}+\mathrm{CHO}$ seems possible, but inefficient given its non-detection in this work.

The presence of $\mathrm{CH}_{3} \mathrm{NH}_{2}$ is best explained by the radical addition reaction $\mathrm{CH}_{3}+\mathrm{NH}_{2}$, a reaction pathway proposed by Garrod et al. (2008). However, reactions of $\mathrm{CH}_{2}$ or NH radicals followed by hydrogenation can not be ruled out:

$\mathrm{CH}_{2}+\mathrm{NH} \rightarrow \mathrm{CH}_{2} \mathrm{NH} \stackrel{+\mathrm{H}}{\longrightarrow} \mathrm{CH}_{3} \mathrm{NH}_{2}$

$\mathrm{CH}_{3}+\mathrm{NH} \rightarrow \mathrm{CH}_{3} \mathrm{NH} \stackrel{+\mathrm{H}}{\longrightarrow} \mathrm{CH}_{3} \mathrm{NH}_{2}$

$\mathrm{CH}_{2}+\mathrm{NH}_{2} \rightarrow \mathrm{CH}_{2} \mathrm{NH}_{2} \stackrel{+\mathrm{H}}{\longrightarrow} \mathrm{CH}_{3} \mathrm{NH}_{2}$

The formation of an intermediate radical is of interest for the formation of $\mathrm{CH}_{3} \mathrm{NHCO}$, as mentioned earlier, but it also opens up another pathway for $\mathrm{CH}_{3} \mathrm{NCO}$ formation. Cernicharo et al. (2016) and Ligterink et al. (2017) suggest the solid-state reaction $\mathrm{CH}_{3}+\mathrm{NCO}$, but an alternative could be:

$\mathrm{CH}_{3} \mathrm{NH}+\mathrm{CO} \rightarrow \mathrm{CH}_{3} \mathrm{NHCO} \stackrel{-\mathrm{H}}{\longrightarrow} \mathrm{CH}_{3} \mathrm{NCO}$

which shows some similarity with the formation mechanism via a $\mathrm{HCN}^{\cdots} \mathrm{CO}$ van der Waals complex in combination with hydrogenation, proposed by Majumdar et al. (2018) to be the dominant pathway to form $\mathrm{CH}_{3} \mathrm{NCO}$ in interstellar ice mantles.

The identified experimental reaction pathways lead to the interstellar ice reaction scheme presented in Fig. 14. Starting from atomic nitrogen, $\mathrm{NH}, \mathrm{NH}_{2}$ and $\mathrm{NH}_{3}$, a variety of reactions, mainly with $\mathrm{CO}$ and $\mathrm{CHO}$, form $\mathrm{HNCO}$, $\mathrm{CH}_{3} \mathrm{NCO}, \mathrm{NH}_{2} \mathrm{CHO}, \mathrm{CH}_{3} \mathrm{C}(\mathrm{O}) \mathrm{NH}_{2}$ and $\mathrm{NH}_{2} \mathrm{C}(\mathrm{O}) \mathrm{NH}_{2}$. $\mathrm{CH}_{3} \mathrm{NH}_{2}$ is formed from $\mathrm{CH}_{x}+\mathrm{NH}_{y}$ radical addition reactions, followed by hydrogenation if necessary. In the experiment, far-UV radiation is used to produce the radicals from $\mathrm{CH}_{4}$ and $\mathrm{HNCO}$. On interstellar dust grains these radicals can also be formed in hydrogenation sequences of carbon 


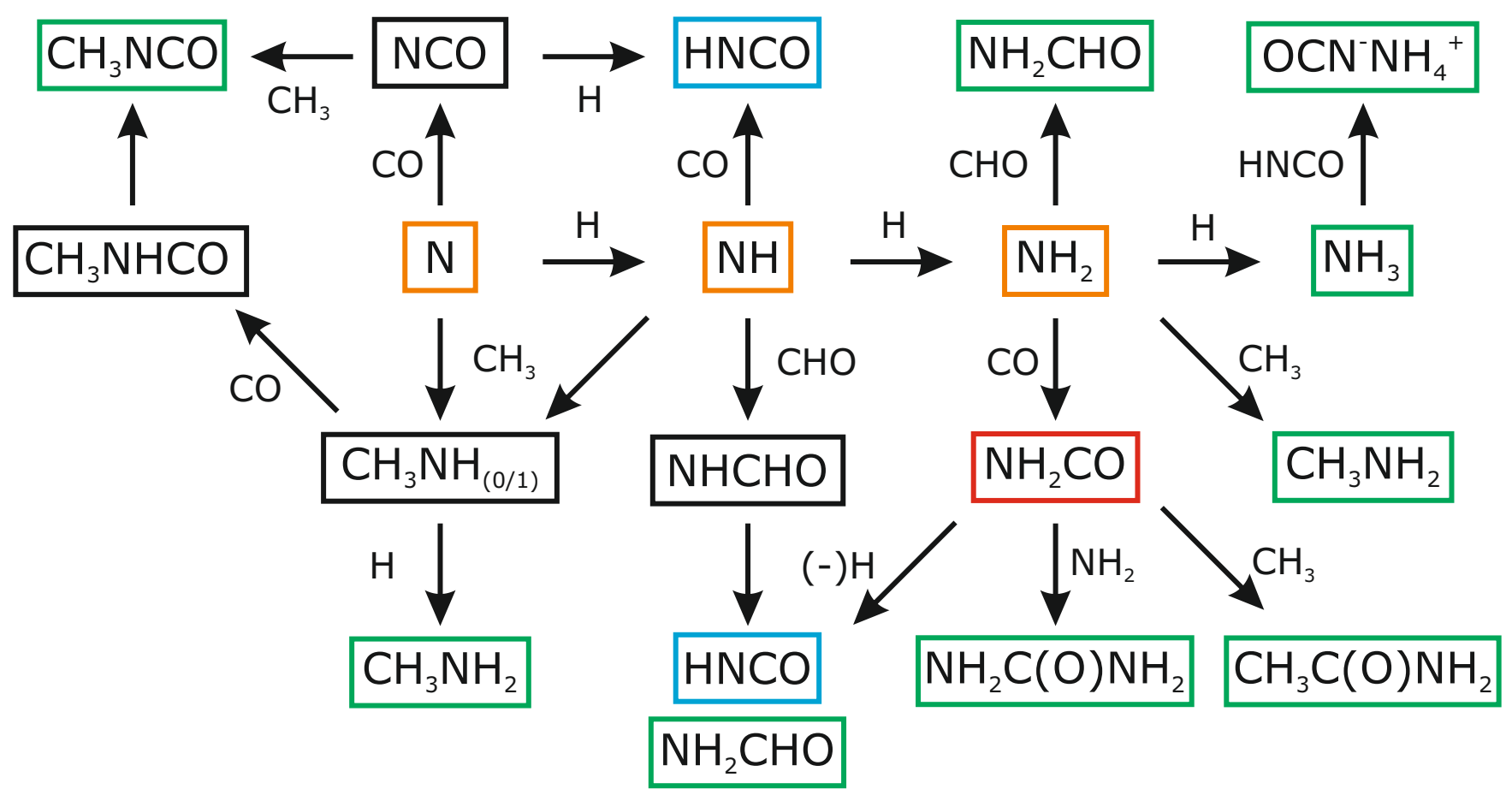

Figure 14. Proposed solid-state reaction scheme for the formation of the smallest generation of amides and $\mathrm{CH}_{3} \mathrm{NH}_{2}$, based on the findings of this work. The reactions derive from the nitrogen hydrogenation back bone (orange boxes). Green boxes indicate the products detected in the experiments, while the experimental precursor species $\mathrm{HNCO}$ is given in a blue box. $\mathrm{CH}_{3} \mathrm{~N}_{0 / 1}$ indicates an intermediary product that is either the $\mathrm{CH}_{3} \mathrm{~N}$ or $\mathrm{CH}_{3} \mathrm{NH}$ radical.

and nitrogen atoms. In interstellar ice, HNCO is likely not at the basis of the formation of amides, but rather formed simultaneously.

Whether complex molecules form in the ice mantles on interstellar dust grains or in gas-phase reactions is still an ongoing debate. In this work it was possible to directly compare the ratio of $\left[\mathrm{CH}_{3} \mathrm{C}(\mathrm{O}) \mathrm{NH}_{2}\right] /\left[\mathrm{NH}_{2} \mathrm{CHO}\right]$ in laboratory experiments and observational data, and indicate that their interstellar gas-phase presence, particularly in hot cores, can be explained by formation in interstellar ice mantles and subsequent thermal desorption. However, for these molecules gas-phase formation pathways have been proposed, such as $\mathrm{NH}_{2}+\mathrm{H}_{2} \mathrm{CO} \rightarrow \mathrm{NH}_{2} \mathrm{CHO}+\mathrm{H}$ (Barone et al. 2015; Skouteris et al. 2017). To strengthen the claim that solidstate reactions form amide bearing molecules, more comparisons between observational and laboratory TPD data of the molecules in this network are needed. Detections of these molecules, preferably towards comparatively less complex low-mass YSOs, will aid this process by expanding observational statistics. Experimentally, TPD data on the species that are formed in different solid-state experiments is needed. In the present experiments HNCO is used as a precursor and therefore ratios with respect to this molecule can not be determined. Energetic processing of, for example, $\mathrm{CH}_{4}: \mathrm{CO}: \mathrm{NH}_{3}$ ice mixtures can be employed to circumvent this problem.

\section{CONCLUSIONS}

This work has investigated the solid-state formation of amides and amines in far-UV irradiated $\mathrm{CH}_{4}$ : $\mathrm{HNCO}$ ice mixtures. Observations towards the low-mass sun-like protostar IRAS 16293-2422B were analysed in search of $\mathrm{CH}_{3} \mathrm{NHCHO}$ and $\mathrm{CH}_{3} \mathrm{C}(\mathrm{O}) \mathrm{NH}_{2}$. The conclusions of this work are summarised as follows:

- Acetamide $\left(\mathrm{CH}_{3} \mathrm{C}(\mathrm{O}) \mathrm{NH}_{2}\right)$, formamide $\left(\mathrm{NH}_{2} \mathrm{CHO}\right)$, carbamide $\left(\mathrm{NH}_{2} \mathrm{CONH}_{2}\right)$, methyl isocyanate $\left(\mathrm{CH}_{3} \mathrm{NCO}\right)$ and methylamine $\left(\mathrm{CH}_{3} \mathrm{NH}_{2}\right)$ are shown to simultaneously form in the solid-state, under conditions mimicking those of ice mantels on interstellar dust grains.

- The carbamoyl radical $\left(\mathrm{NH}_{2} \mathrm{CO}\right)$ is identified as an important reaction intermediate in the formation of amides, specifically $\mathrm{CH}_{3} \mathrm{C}(\mathrm{O}) \mathrm{NH}_{2}$ and $\mathrm{NH}_{2} \mathrm{C}(\mathrm{O}) \mathrm{NH}_{2}$.

- $\mathrm{CH}_{3} \mathrm{C}(\mathrm{O}) \mathrm{NH}_{2}$ is tentatively identified in ALMA observations towards the low-mass sun-like protostar IRAS $16293-2422 \mathrm{~B}$ at column densities of $9 \times 10^{14} \mathrm{~cm}^{-2}$ and $25 \times 10^{14} \mathrm{~cm}^{-2}$ for $T_{\mathrm{ex}}=100$ and $300 \mathrm{~K}$, respectively. The resulting ratio of $\left[\mathrm{CH}_{3} \mathrm{C}(\mathrm{O}) \mathrm{NH}_{2}\right] /\left[\mathrm{NH}_{2} \mathrm{CHO}\right]=0.09-0.25$ matches with abundances found towards high-mass YSOs. $\mathrm{CH}_{3} \mathrm{NHCHO}$ is not detected down to an upper limit column density of $\leq 1 \times 10^{15} \mathrm{~cm}^{-2}$.

- A comparison between experimental TPD data and observations of $\mathrm{CH}_{3} \mathrm{C}(\mathrm{O}) \mathrm{NH}_{2}$ and $\mathrm{NH}_{2} \mathrm{CHO}$, indicates that solid-state chemistry on interstellar dust grains likely is responsible for the formation of these two species.

- A solid-state reaction network for the smallest generations of amides and amide-like molecules is proposed, fo- 
cussing on reactions between $\mathrm{N}, \mathrm{NH}$ and $\mathrm{NH}_{2}$ radicals with $\mathrm{CO}$ and $\mathrm{CHO}$, followed by $\mathrm{CH}_{3}$ addition.

\section{ACKNOWLEDGEMENTS}

The authors thank A. Belloche and V. Ilyushin for sharing the rotational spectroscopy files of acetamide and $\mathrm{N}$ methylformamide and for useful discussions on the subject of amide formation. This paper makes use of the following ALMA data: ADS/JAO.ALMA\#2012.1.00712.S, ADS/JAO.ALMA\#2013.1.00278.S and ADS/JAO.ALMA\#2016.1.01150.S. ALMA is a partnership of ESO (representing its member states), NSF (USA) and NINS (Japan), together with NRC (Canada), NSC and ASIAA (Taiwan), and KASI (Republic of Korea), in cooperation with the Republic of Chile. The Joint ALMA Observatory is operated by ESO, AUI/NRAO and NAOJ. NL is funded by the Origins Centre. Astrochemistry in Leiden is supported by the European Union A-ERC grant 291141 CHEMPLAN, by the Netherlands Research School for Astronomy (NOVA) and by a Royal Netherlands Academy of Arts and Sciences (KNAW) professor prize. CryoPAD2 was realized with NOVA and NWO (Netherlands Organisation for Scientific Research) grants, including a NWO-M grant, a NWO-Vici grant and funding through the Dutch Astrochemistry Network II. JKJ acknowledges support from the European Research Council (ERC) under the European Union's Horizon 2020 research and innovation programme (grant agreement No 646908) through ERC Consolidator Grant "S4F".

\section{References}

Adande G. R., Woolf N. J., Ziurys L. M., 2013, Astrobiology, 13, 439

Agarwal V. K., Schutte W., Greenberg J. M., Ferris J. P., Briggs R., Connor S., van de Bult C. P. E. M., Baas F., 1985, Origins of Life, 16,21

Altwegg K., et al., 2017, MNRAS, 469, S130

Barone V., Latouche C., Skouteris D., Vazart F., Balucani N., Ceccarelli C., Lefloch B., 2015, MNRAS, 453, L31

Belloche A., Menten K. M., Comito C., Müller H. S. P., Schilke P., Ott J., Thorwirth S., Hieret C., 2008, A\&A, 482, 179

Belloche A., Müller H. S. P., Menten K. M., Schilke P., Comito C., 2013, A\&A, 559, A47

Belloche A., et al., 2017, A\&A, 601, A49

Berger R., 1961, Proceedings of the National Academy of Science, 47, 1434

Bergner J. B., Öberg K. I., Garrod R. T., Graninger D. M., 2017, ApJ, 841, 120

Bernstein M. P., Sandford S. A., Allamandola L. J., Chang S., Scharberg M. A., 1995, ApJ, 454, 327

Bisschop S. E., Jørgensen J. K., van Dishoeck E. F., de Wachter E. B. M., 2007, Astronomy and Astrophysics, 465, 913

Bockelée-Morvan D., et al., 2000, A\&A, 353, 1101

Bogan D. J., Hand C. W., 1971, The Journal of Physical Chemistry, 75, 1532

Boogert A. C. A., Schutte W. A., Helmich F. P., Tielens A. G. G. M., Wooden D. H., 1997, A\&A, 317, 929

Bossa J. B., Borget F., Duvernay F., Danger G., Theulé P., Chiavassa T., 2012, Aust. J. Chem., 65, 129-137

Bossa J.-B., Paardekooper D. M., Isokoski K., Linnartz H., 2015,
Physical Chemistry Chemical Physics (Incorporating Faraday Transactions), 17, 17346

Bouilloud M., Fray N., Bénilan Y., Cottin H., Gazeau M.-C., Jolly A., 2015, MNRAS, 451, 2145

Caselli P., Ceccarelli C., 2012, Astron. Astrophys. Rev., 20, 56

Cazaux S., Tielens A. G. G. M., Ceccarelli C., Castets A., Wakelam V., Caux E., Parise B., Teyssier D., 2003, ApJL, 593, L51

Cernicharo J., et al., 2016, A\&A, 587, L4

Chaabouni H., Diana S., Nguyen T., Dulieu F., 2018, A\&A, 612, A47

Collings M. P., Anderson M. A., Chen R., Dever J. W., Viti S., Williams D. A., McCoustra M. R. S., 2004, MNRAS, 354, 1133

Corby J. F., et al., 2015, MNRAS, 452, 3969

Coutens A., et al., 2016, A\&A, 590, L6

Coutens A., et al., 2018, A\&A, 612, A107

Cruz-Diaz G. A., Muñoz Caro G. M., Chen Y.-J., Yih T.-S., 2014, A\&A, 562, A120

Fedoseev G., Ioppolo S., Zhao D., Lamberts T., Linnartz H., 2015, MNRAS, 446, 439

Fedoseev G., Chuang K.-J., van Dishoeck E. F., Ioppolo S., Linnartz H., 2016, MNRAS, 460, 4297

Fedoseev G., Scirè C., Baratta G. A., Palumbo M. E., 2018, MNRAS, 475, 1819

Förstel M., Maksyutenko P., Jones B. M., Sun B. J., Lee H. C., Chang A. H. H., Kaiser R. I., 2016, ApJ, 820, 117

Garrod R. T., 2013, ApJ, 765, 60

Garrod R. T., Widicus Weaver S. L., Herbst E., 2008, ApJ, 682, 283

Gerakines P. A., Hudson R. L., 2015, ApJL, 805, L20

Gerakines P. A., Schutte W. A., Ehrenfreund P., 1996, A\&A, 312, 289

Gerakines P. A., Moore M. H., Hudson R. L., 2004, Icarus, 170, 202

Gibb E. L., Whittet D. C. B., Boogert A. C. A., Tielens A. G. G. M., 2004, ApJ, 151, 35

Goesmann F., et al., 2015, Science, 349

Gupta D., Naghma R., Antony B., 2014, Molecular Physics, 112, 1201

Hagen W., Allamandola L. J., Greenberg J. M., 1979, Ap\&SS, 65,215

Halfen D. T., Ilyushin V., Ziurys L. M., 2011, ApJ, 743, 60

Halfen D. T., Ilyushin V. V., Ziurys L. M., 2015, ApJl, 812, L5

Henderson B. L., Gudipati M. S., 2015, ApJ, 800, 66

Herbst E., van Dishoeck E. F., 2009, ARA\&A, 47, 427

Hollis J. M., Jewell P. R., Lovas F. J., Remijan A., 2004, ApJL, $613, \mathrm{~L} 45$

Hollis J. M., Lovas F. J., Remijan A. J., Jewell P. R., Ilyushin V. V., Kleiner I., 2006, ApJL, 643, L25

Hudgins D. M., Sandford S. A., Allamandola L. J., Tielens A. G. G. M., 1993, ApJs, 86, 713

Ilyushin V. V., Alekseev E. A., Dyubko S. F., Kleiner I., Hougen J. T., 2004, Journal of Molecular Spectroscopy, 227, 115

Islam F., Baratta G. A., Palumbo M. E., 2014, A\&A, 561, A73

Jones B. M., Bennett C. J., Kaiser R. I., 2011, ApJ, 734, 78

Jørgensen J. K., Favre C., Bisschop S. E., Bourke T. L., van Dishoeck E. F., Schmalzl M., 2012, ApJl, 757, L4

Jørgensen J. K., et al., 2016, A\&A, 595, A117

Kahane C., Ceccarelli C., Faure A., Caux E., 2013, ApJl, 763, L38

Kaifu N., Morimoto M., Nagane K., Akabane K., Iguchi T., Takagi K., 1974, ApJL, 191, L135

Kaňuchová Z., Urso R. G., Baratta G. A., Brucato J. R., Palumbo M. E., Strazzulla G., 2016, A\&A, 585, A155

Lacy J. H., Baas F., Allamandola L. J., van de Bult C. E. P., Persson S. E., McGregor P. J., Lonsdale C. J., Geballe T. R., 1984, ApJ, 276, 533 
Ligterink N. F. W., Paardekooper D. M., Chuang K.-J., Both M. L., Cruz-Diaz G. A., van Helden J. H., Linnartz H., 2015, A\&A, 584, A56

Ligterink N. F. W., et al., 2017, MNRAS, 469, 2219

Ligterink N. F. W., Walsh C., Bhuin R. G., Vissapragada S., van Scheltinga J. T., Linnartz H., 2018, A\&A, 612, A88

Ligterink N. F. W., et al., 2018, subm., A\&A

López-Sepulcre A., et al., 2015, MNRAS, 449, 2438

Lykke J. M., et al., 2017, A\&A, 597, A53

Majumdar L., Loison J.-C., Ruaud M., Gratier P., Wakelam V., Coutens A., 2018, MNRAS, 473, L59

Martín-Doménech R., Rivilla V. M., Jiménez-Serra I., Quénard D., Testi L., Martín-Pintado J., 2017, MNRAS, 469, 2230

Martín S., Mauersberger R., Martín-Pintado J., Henkel C., García-Burillo S., 2006, ApJS, 164, 450

Maté B., Molpeceres G., Timón V., Tanarro I., Escribano R., Guillemin J. C., Cernicharo J., Herrero V. J., 2017, MNRAS, 470,4222

Muñoz Caro G. M., Dartois E., Boduch P., Rothard H., Domaracka A., Jiménez-Escobar A., 2014, A\&A, 566, A93

Müller H. S. P., Thorwirth S., Roth D. A., Winnewisser G., 2001, A\&A, 370, L49

Müller H. S. P., Schlöder F., Stutzki J., Winnewisser G., 2005, Journal of Molecular Structure, 742, 215

Neill J. L., et al., 2014, The Astrophysical Journal, 789, 8

Noble J. A., et al., 2015, A\&A, 576, A91

Pickett H. M., Poynter R. L., Cohen E. A., Delitsky M. L., Pearson J. C., Müller H. S. P., 1998, J. Quant. Spectrosc. Radiative Transfer, 60, 883

Quan D., Herbst E., 2007, A\&A, 474, 521

Quénard D., Jiménez-Serra I., Viti S., Holdship J., Coutens A., 2018, MNRAS, 474, 2796

Raunier S., Chiavassa T., Duvernay F., Borget F., Aycard J. P., Dartois E., d'Hendecourt L., 2004, A\&A, 416, 165

Remijan A. J., et al., 2014, ApJ, 783, 77

Shen C. J., Greenberg J. M., Schutte W. A., van Dishoeck E. F., 2004, A\&A, 415, 203

Skouteris D., Vazart F., Ceccarelli C., Balucani N., Puzzarini C., Barone V., 2017, MNRAS, 468, L1

Turner B. E., 1991, ApJS, 76, 617

Turner B. E., Liszt H. S., Kaifu N., Kisliakov A. G., 1975, ApJL, 201, L149

Wexler A., 1967, Applied Spectroscopy Reviews, 1, 29

van Broekhuizen F. A., Keane J. V., Schutte W. A., 2004, A\&A, 415,425

van Broekhuizen F. A., Pontoppidan K. M., Fraser H. J., van Dishoeck E. F., 2005, A\&A, 441, 249

\section{APPENDIX A: ADDITIONAL MASS SPECTROMETRIC REFERENCE DATA}

Figure A1 shows the TPD trace of formamide $\left(\mathrm{NH}_{2} \mathrm{CHO}\right)$ between 150 and $300 \mathrm{~K}$. The peak desorption temperature is found at $210 \mathrm{~K}$. Figure A2 shows a comparison of the $\mathrm{N}$-methylformamide $\left(\mathrm{CH}_{3} \mathrm{NHCHO}\right)$ and acetamide $\left(\mathrm{CH}_{3} \mathrm{C}(\mathrm{O}) \mathrm{NH}_{2}\right)$ fragmentation pattern between in situ measurements on CryoPAD2 and reference data from the NIST database, both normalised to the main mass $m / z 59$. Mainly small deviations in the pattern intensity are seen, with the notable exception of the $\mathrm{m} / z 44$ and 17 fragments of $\mathrm{CH}_{3} \mathrm{C}(\mathrm{O}) \mathrm{NH}_{2}$ which show large discrepancies compared to the NIST data. Throughout this work the in situ measured fragmentation patterns of $\mathrm{CH}_{3} \mathrm{NHCHO}$ and $\mathrm{CH}_{3} \mathrm{C}(\mathrm{O}) \mathrm{NH}_{2}$ will be used.

Figure A3 shows the TPD trace of $\mathrm{m} / \mathrm{z} 43$ and 42 over

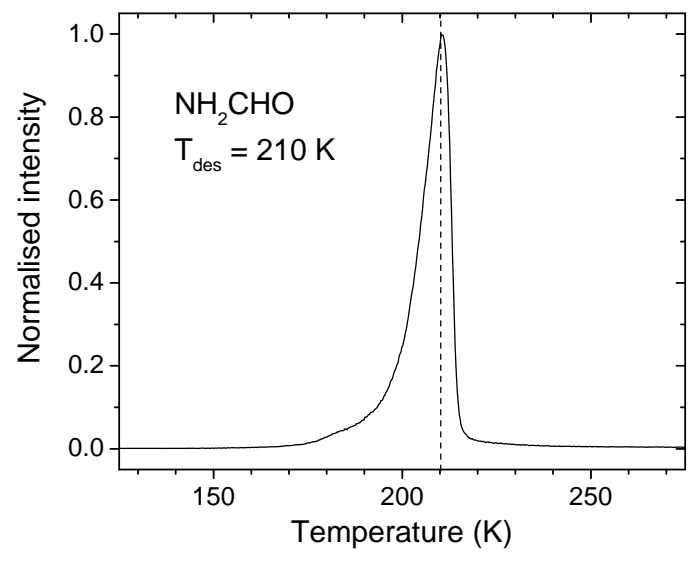

Figure A1. TPD trace of $m / z 45$ of $\mathrm{NH}_{2} \mathrm{CHO}$.

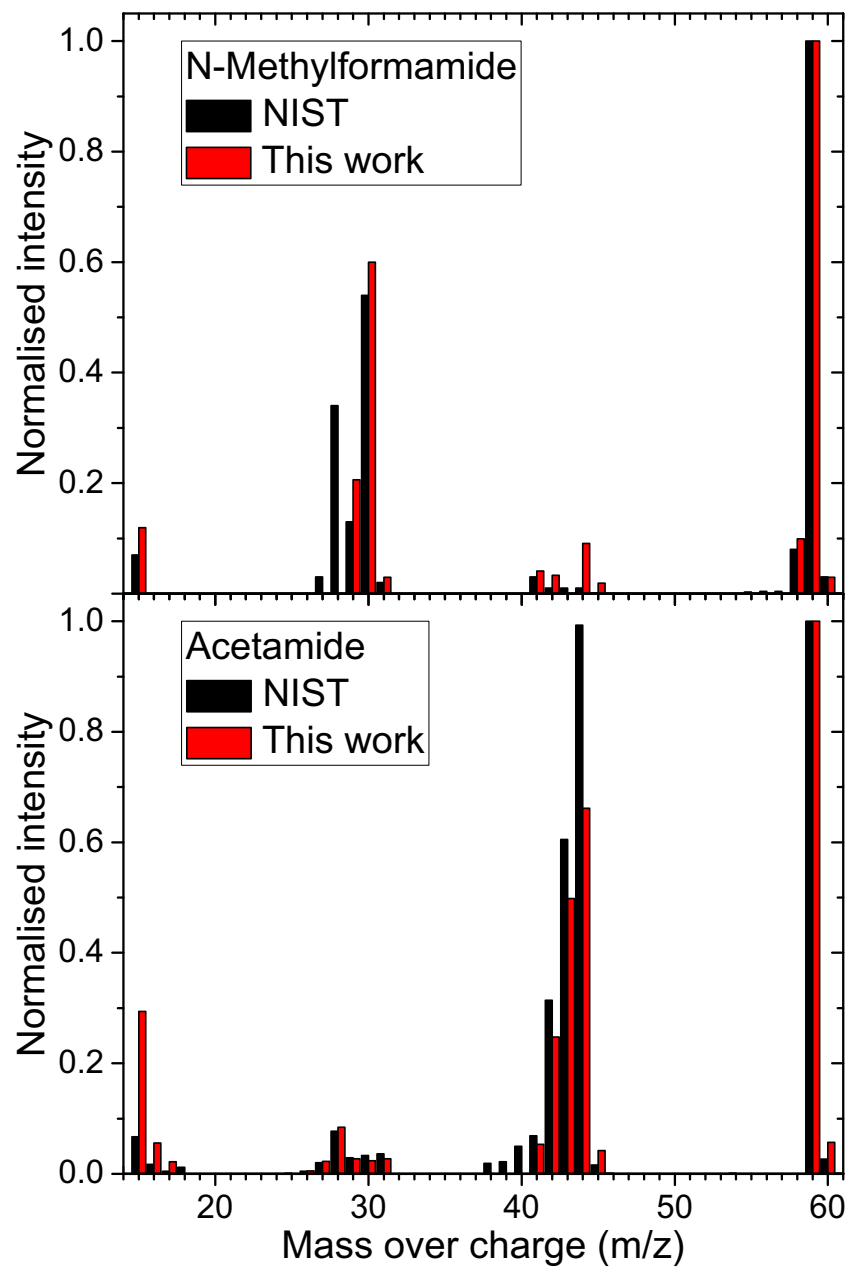

Figure A2. Fragmentation pattern comparison between NIST data (black) and values measured in this work for Nmethylformamide $\left(\mathrm{CH}_{3} \mathrm{NHCHO}\right.$, top in red) and acetamide $\left(\mathrm{CH}_{3} \mathrm{C}(\mathrm{O}) \mathrm{NH}_{2}\right.$, bottom in red). 
Table A1. Mass fragmentation patterns of $\mathrm{NH}_{3}, \mathrm{HNCO}, \mathrm{NH}_{2} \mathrm{CHO}, \mathrm{CH}_{3} \mathrm{C}(\mathrm{O}) \mathrm{NH}_{2}$ and $\mathrm{CH}_{3} \mathrm{NHCHO}$ at selected masses.

\begin{tabular}{lllllll}
\hline \hline$m / z$ & $\mathrm{NH}_{3}$ & $\mathrm{HNCO}^{a}$ & $\mathrm{CH}_{3} \mathrm{NH}_{2}$ & $\mathrm{NH}_{2} \mathrm{CHO}$ & $\mathrm{CH}_{3} \mathrm{C}(\mathrm{O}) \mathrm{NH}_{2}{ }^{b}$ & $\mathrm{CH}_{3} \mathrm{NHCHO}^{b}$ \\
\hline 15 & 0.08 & 0.07 & 0.04 & 0.01 & 0.29 & 0.12 \\
16 & 0.80 & - & - & 0.12 & 0.06 & - \\
17 & 1.00 & - & 0.01 & 0.33 & 0.02 & - \\
27 & - & 0.02 & 0.08 & 0.08 & 0.02 & - \\
28 & - & 0.07 & 0.54 & 0.06 & 0.08 & - \\
29 & - & 0.14 & 0.12 & 0.34 & 0.03 & 0.21 \\
30 & - & 0.02 & 1.00 & 0.01 & 0.02 & 0.21 \\
31 & - & - & 0.66 & - & 0.03 & 0.03 \\
42 & - & 0.22 & - & 0.02 & 0.25 & 0.03 \\
43 & - & 1.00 & - & 0.11 & 0.50 & - \\
44 & - & 0.02 & - & 0.25 & 0.66 & 0.09 \\
45 & - & - & - & 1.00 & 0.04 & 0.02 \\
59 & - & - & - & - & 1.00 & 1.00 \\
\hline
\end{tabular}

Notes. ${ }^{a}$ Fragmentation pattern from Bogan \& Hand (1971), ${ }^{b}$ Fragmentation pattern measured in this work. Other fragmentation patterns are adapted from the NIST database.

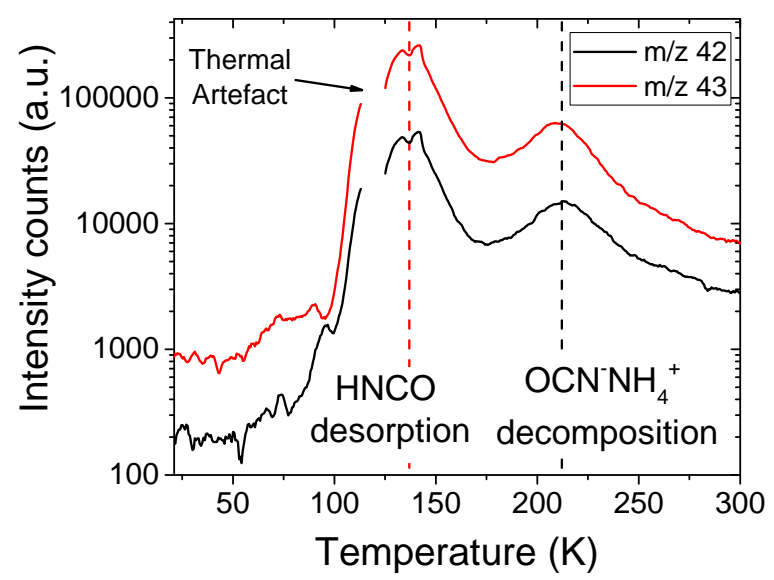

Figure A3. TPD trace of $m / z 43$ and 42 of HNCO.

the full temperature range of 20 to $300 \mathrm{~K}$. The data from Exp. 1, also displayed in Fig. 5, are used. The data shows the main thermal desorption peak of $\mathrm{HNCO}$ at $~ 130 \mathrm{~K}$, after which HNCO gas present in the vacuum chamber is being pumped away, resulting in a trailing slope. At $\sim 210 \mathrm{~K}$, the $\mathrm{m} / \mathrm{z} 43$ and 42 increase again, resulting in a small peak on top of the trailing slope. This increase is the result of the thermal decomposition of $\mathrm{OCN}^{-} \mathrm{NH}_{4}^{+}$and $\mathrm{OCN}^{-} \mathrm{CH}_{3} \mathrm{NH}_{3}^{+}$ and subsequent release of $\mathrm{HNCO}$ to the gas-phase.

\section{APPENDIX B: OBSERVED ROTATIONAL TRANSITIONS OF ACETAMIDE}

This paper has been typeset from a $\mathrm{T}_{\mathrm{EX}} / \mathrm{LAT}_{\mathrm{EX}}$ file prepared by the author. 
18 N. F. W. Ligterink et al.

Table B1. Identified $\mathrm{CH}_{3} \mathrm{C}(\mathrm{O}) \mathrm{NH}_{2}$ lines towards IRAS 16293-2422B

\begin{tabular}{llllll}
\hline \hline $\begin{array}{l}\text { Upper state } \\
J^{\prime} K_{a}^{\prime} K_{b}^{\prime}\end{array}$ & $\begin{array}{l}\text { Lower state } \\
J^{\prime \prime} K_{a}^{\prime \prime} K_{b}^{\prime \prime}\end{array}$ & $\begin{array}{l}\text { Frequency } \\
(\mathrm{MHz})\end{array}$ & $\begin{array}{l}E_{\mathrm{up}} \\
(\mathrm{K})\end{array}$ & $\begin{array}{l}A_{\mathrm{ij}} \\
\left(\times 10^{-5} \mathrm{~s}^{-1}\right)\end{array}$ & Line blending \\
\hline 16610 & 1579 & 225150.6 & 112.5 & 44.9 & $\mathrm{HCOCH} \mathrm{HH}_{2} \mathrm{OH}$ \\
16710 & 1569 & 225218.9 & 112.5 & 45.0 & unblended \\
20417 & 19416 & 236203.3 & 140.0 & 5.2 & gGg' $\left(\mathrm{CH}_{2} \mathrm{OH}\right)_{2}$ \\
20317 & 19316 & 236203.3 & 140.0 & 5.2 & gGg' $\left(\mathrm{CH}_{2} \mathrm{OH}\right)_{2}$ \\
20317 & 19416 & 236203.3 & 140.0 & 77.0 & gGg $\left(\mathrm{CH}_{2} \mathrm{OH}\right)_{2}$ \\
20417 & 19316 & 236203.3 & 140.0 & 77.0 & gGg' $\left(\mathrm{CH}_{2} \mathrm{OH}\right)_{2}$ \\
21219 & 20318 & 239780.3 & 143.9 & 1.5 & unblended \\
21219 & 20218 & 239780.3 & 143.9 & 90.4 & unblended \\
21319 & 20218 & 239780.3 & 143.9 & 1.5 & unblended \\
21319 & 20318 & 239780.3 & 143.9 & 90.4 & unblended \\
\hline
\end{tabular}

Notes. Parameters adapted from Ilyushin et al. (2004). 